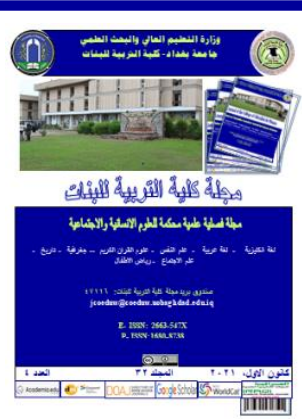

Received: October 11, 2021

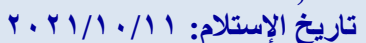

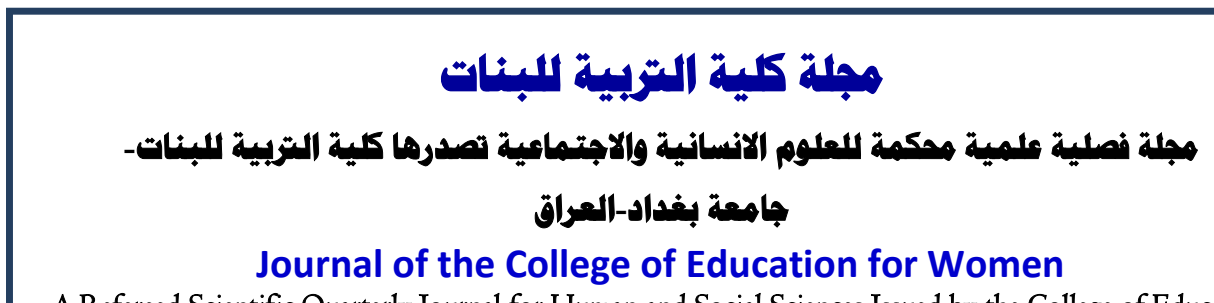

A Refereed Scientific Quarterly Journal for Human and Social Sciences Issued by the College of Education for Women-University of Baghdad-IRAQ

DOI: https://doi.org/10.36231/coedw.v32i4.1545

Accepted: December 20, 2021

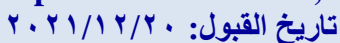

Published: December 29, 2021

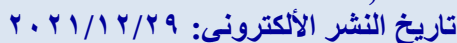

\section{Employment and Labor Union Laws in Japan between the 1889 and 1946 Constitutions: A Comparative Study}

\author{
Afrah Mohammed Ali \\ History Department- College of Arts- \\ Mustansiriyah University \\ afrahm@uomustansiriyah.edu.iq
}

\section{Abstract}

This research is based on the descriptive and analytical methodology. The importance of studying labor laws and labor unions in Japan between 1889 and 1946 constitutions is because Japan was out of a feudal phase, and had no idea about the factory system and industrialization in their modern sense before the Meiji era. Generally, its labor system used to be mostly familial, and the economic system was based on agriculture. This called for the enactment of legislations and laws appropriate for the coming phase in Meiji era. Thus, this paper examines the role of Meiji government in enacting labor legislations and laws when he came to power in 1896, and his new constitution in 1889 and the civil code of 1896. It further examines the way Meiji government and the following Japanese governments until the end of World War II did not abide by Meiji laws and stipulations of the constitution with their abusive actions in ending the workers' strikes and disputes, with the inequality between genders in labor and wages, and the use of child labor in factories in an inhuman way. The paper clarifies the role of the American occupation of Japan (1945-1952) after dissolving Meiji constitution and legislations and the government measures that followed them to enact new legislations, laws and constitution for Japan on November 3, 1946, which was active in May 3, 1947. The paper has concluded that the American occupation policy of Japan was able to avoid the dissidence of millions of Japanese workers, whose level of livelihood was deteriorating after their country lost the war, and convert them from a dissident group against the occupation to a peaceful group which did not target the occupation in their future goals.

$$
\begin{aligned}
& \text { قوانين العمل والحركات العمالية في اليابان بين }
\end{aligned}
$$

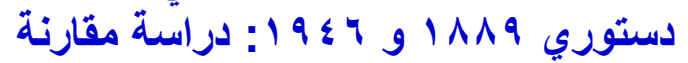

$$
\begin{aligned}
& \text { أفراح محمد علي الجئ. } \\
& \text { قسم التاريخـ كلية الآدابـ الجامعية المستنصرية } \\
& \text { afrahm@uomustansiriyah.edu.iq }
\end{aligned}
$$

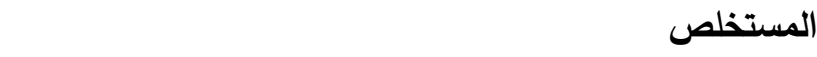

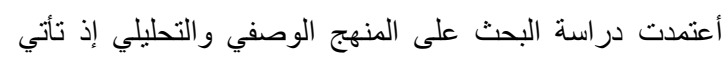

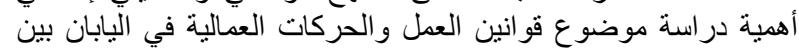

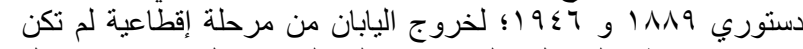

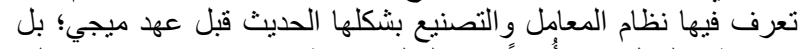

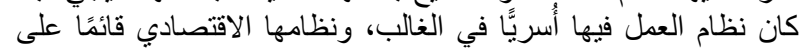

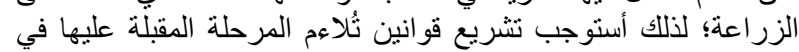

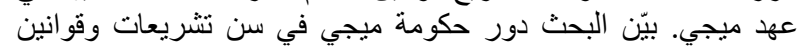

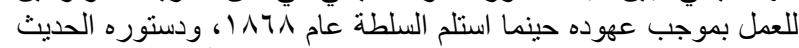

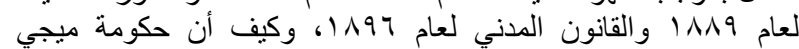

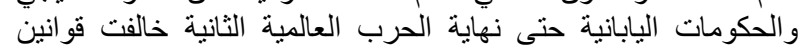

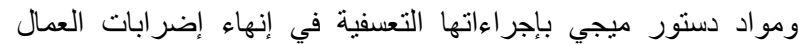

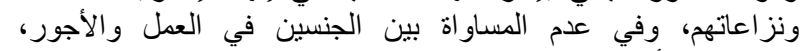

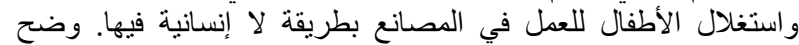

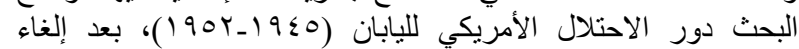

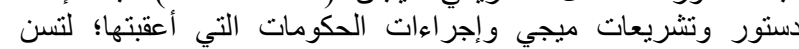

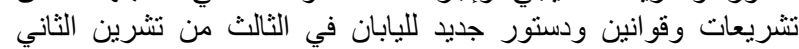

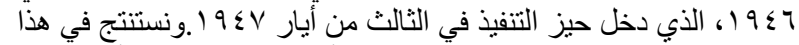

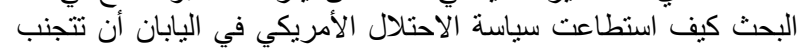

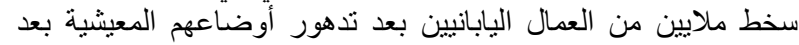

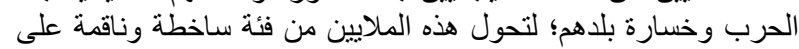

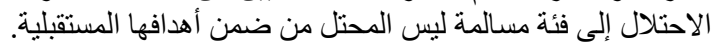

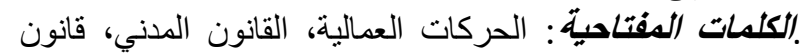

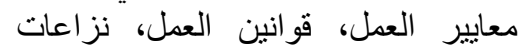
العمل 


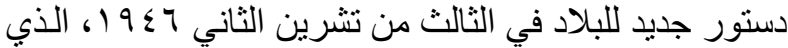

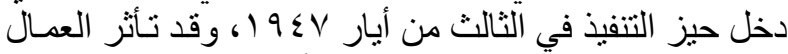

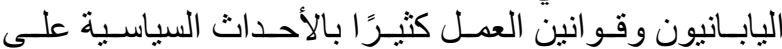

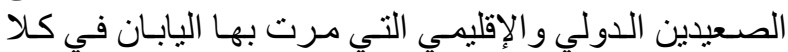

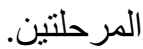

وسنبين في هذا البحث مـا الإجر اءات التي اتخذنتها

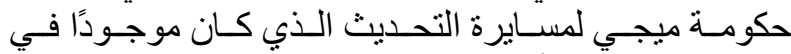
الو لايات المتحدة الأمريكية و العالم الغربي؟ وما التئي القو انين التي

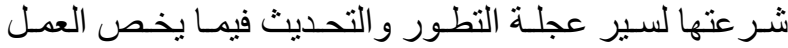

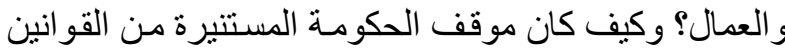

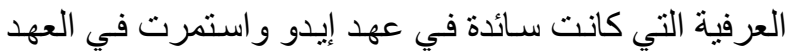

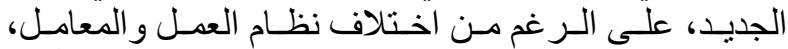

و الاختلاف في المجتمع في عهذ ميجي عما كان عليه سابقًا.

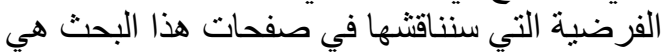

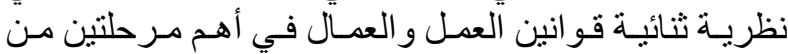

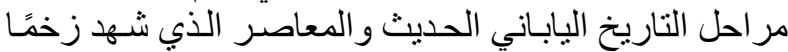

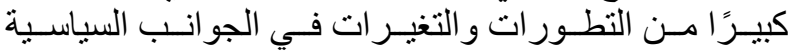

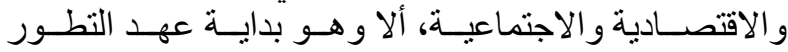

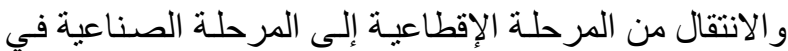

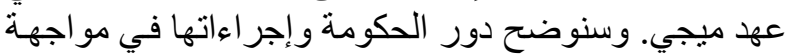
منطلبات ألعمال من كلا الجنسين في المعامل، وكيف واعل واجهات

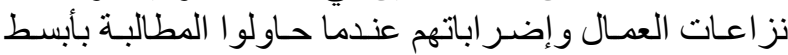

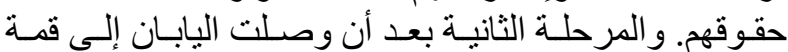

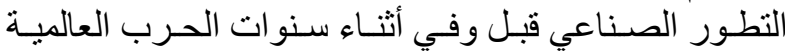

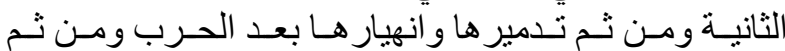

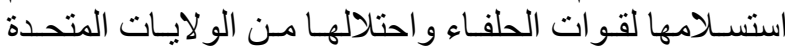

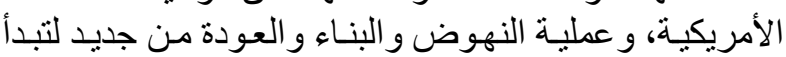
عملية الإحياء وبناء اليابان في ظل تشريعات ولئ وقو انين المحتل بعد عام 19 19 الإناء

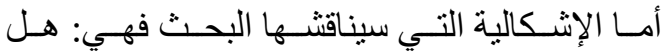
أنصفت حكومة ميجي التي سعت إلى التطور و التحديث في

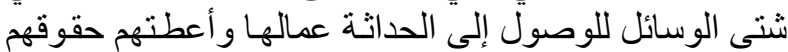

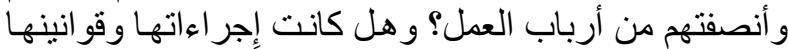

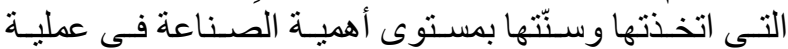

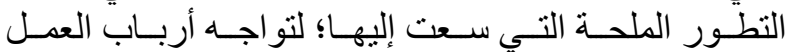

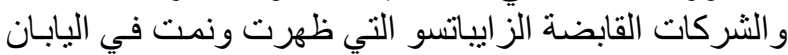

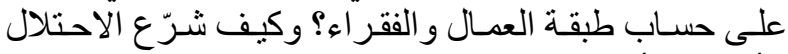

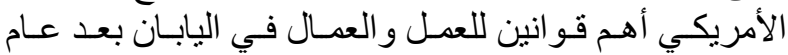

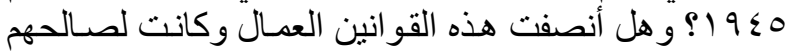

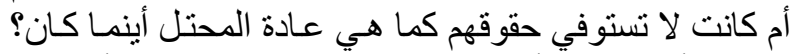

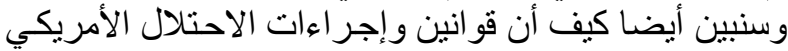

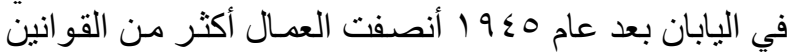

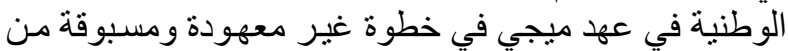

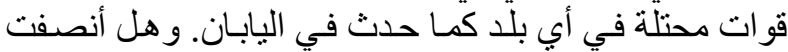

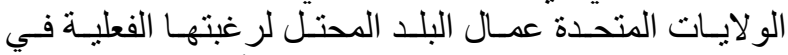

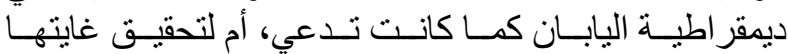
وسياستها في السيطرة على شريحة العمال التي تشكل نسبة التهان
Keywords: civil code, labor disputes, labor laws, labor law standards, labor movements

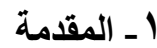

تعود جذور التجربة اليابانية الحديثة إلى عهد ميجي

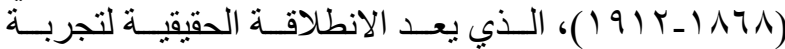
التحديث التي عرفتها اليابان في الوقت الحديث، إذ شهر عهد

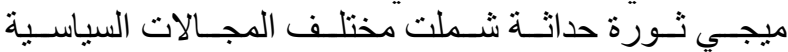

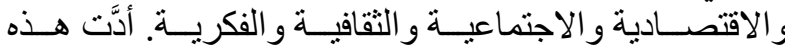

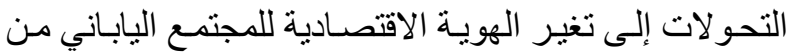

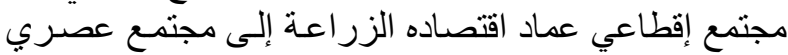

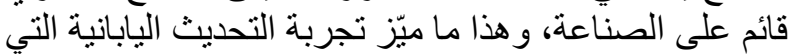

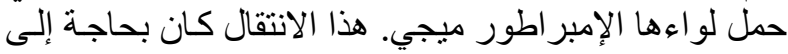

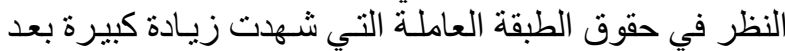

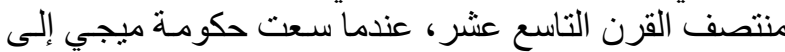
استقطاب الفلاحبن من القرى إلى المئ المدن؛ لتحويل الفيلاحين

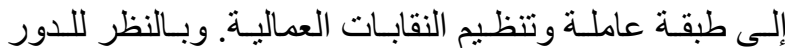

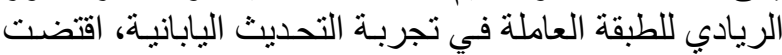

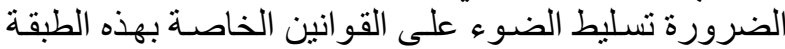

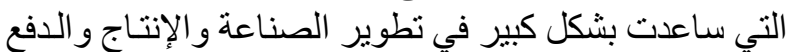

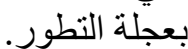

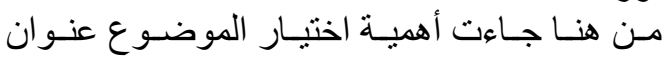

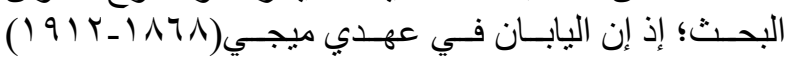

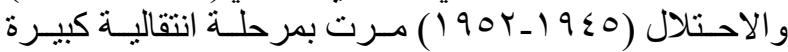
يمكن القول عنها: إنها شملت نوالوالي احي الحياة جميعها. المرحلة

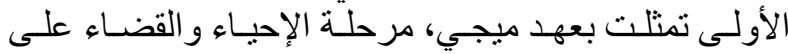

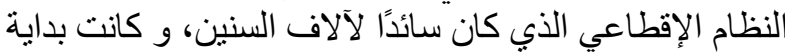

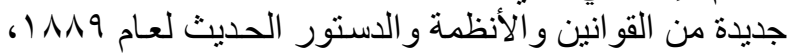

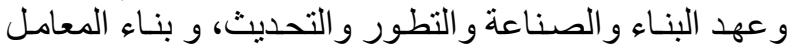

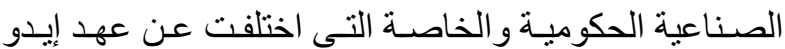

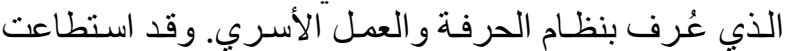

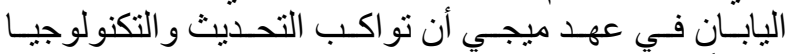

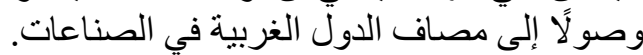

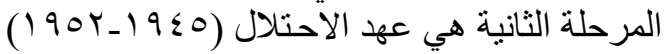

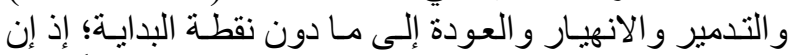
اليابان عندما تطورت في عهذ ميجي لم تكن بلدًا محتلًا، بل الـل

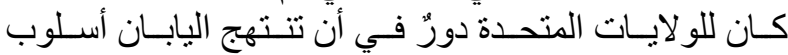

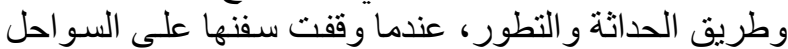

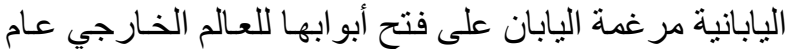

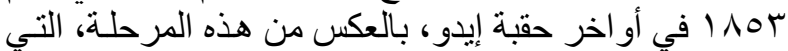

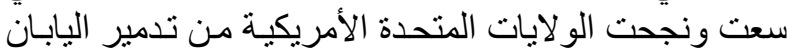

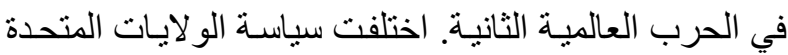

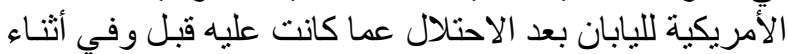

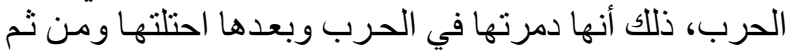

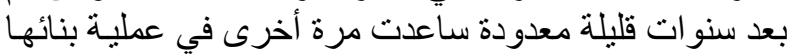

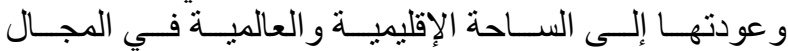

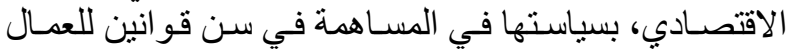

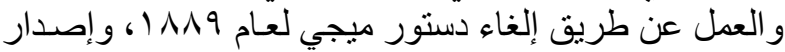




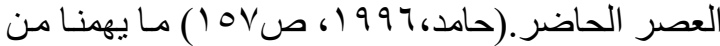

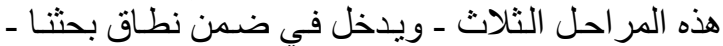

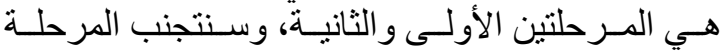

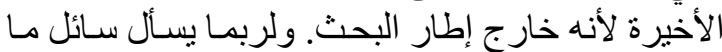

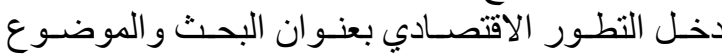

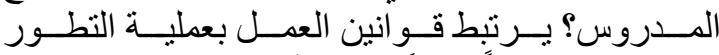

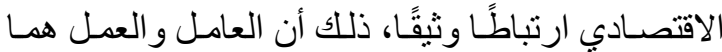

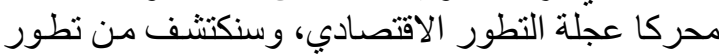

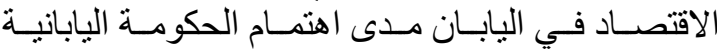

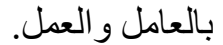

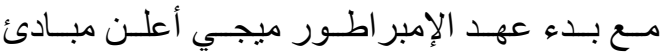

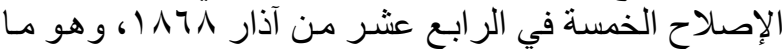

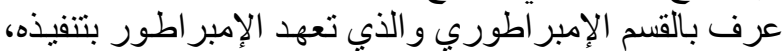

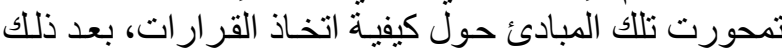

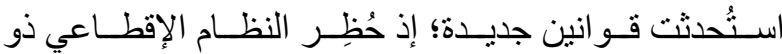
الامتياز ات والطبقات ونظام الطبقات الاجتماعية، و إعلان أن أن الناع

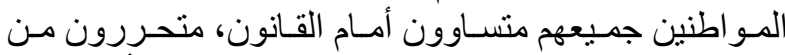

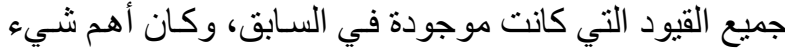

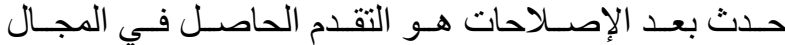

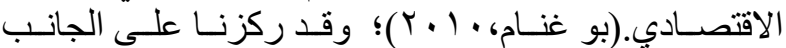
الاقتصادي على وفق ما يقتضيه البحث.

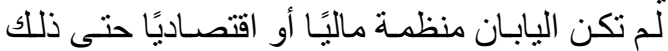
الحين على وفق الأساليب الحديثة، وكانت هناكي الك مصاعب التبان في

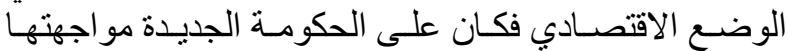

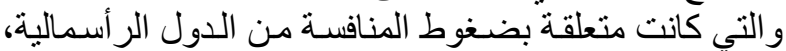

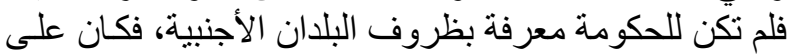

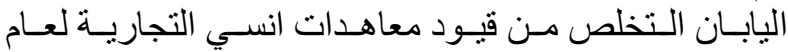

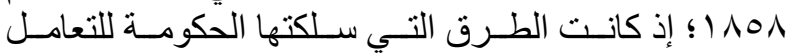

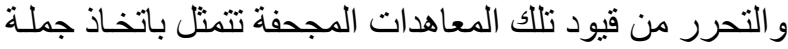

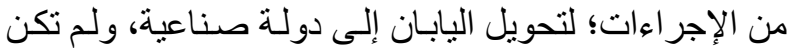

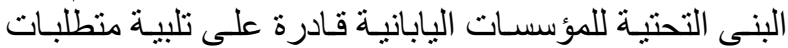

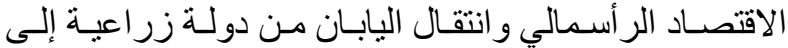

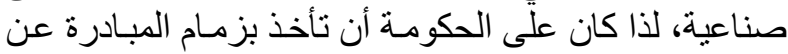

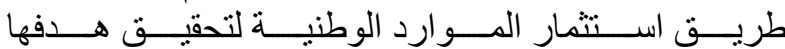

المنشود.(Matsuoka, 1931) شـهـ النصف الأول مـن مرحلـة النمـو الاقتصـادي

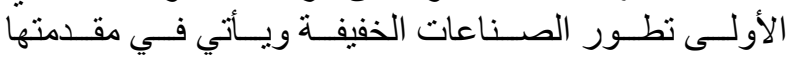

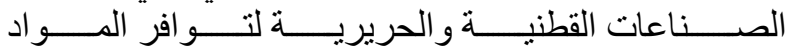

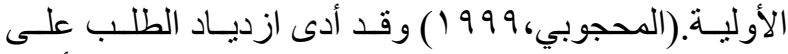

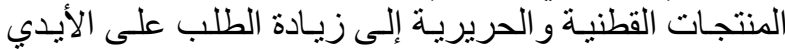

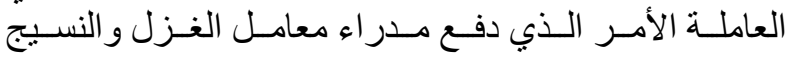

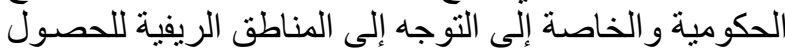

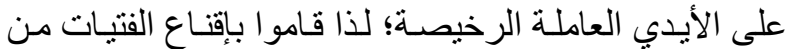
عو ائل السامور اي و الفلاحين الأغنياء بـ: "الغزل والئل النسيج من

اجل الوطن." (Nafzige, 2016) كانـت الغالبيـة مـن النســاء العـاملات مـن العو ائسل

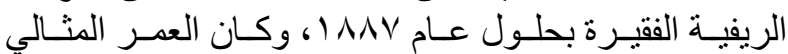

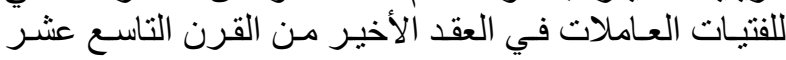

كبيرة من المجتمع اليابـاني؛ لإدامـة وخدمة سياستها في هذا البلد؟

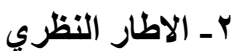

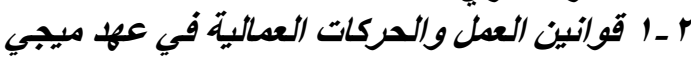

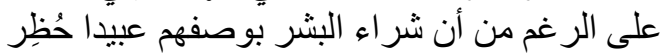

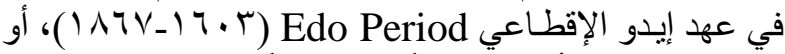

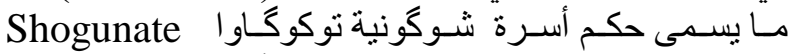
Tokugawa

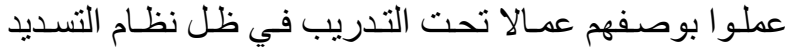
شبه الإقطاعي، و كان عمـال الإنتاج الثباب في نهايـة عهد

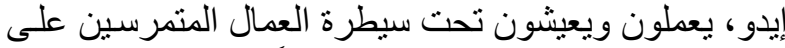

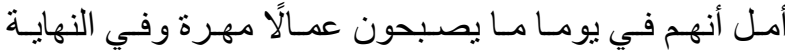

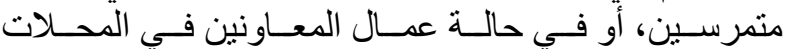

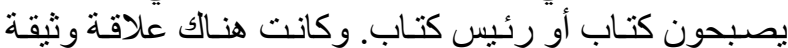
بين العامل المتمرس و العامل الذي تحت الته التدريب و التي كانت

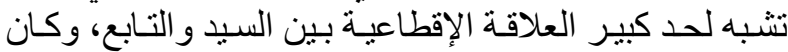

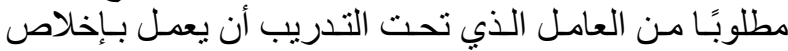

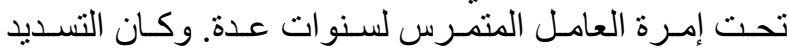

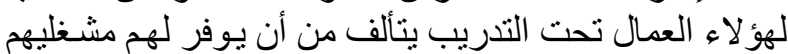

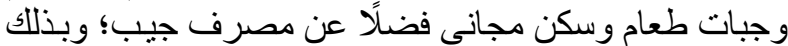

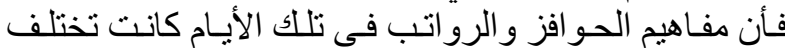

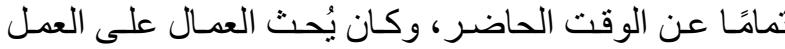

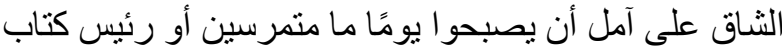

أكثر من إغر اء الر اتب (Hotani \& Hayashi,1961).

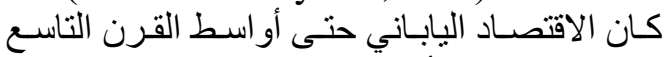

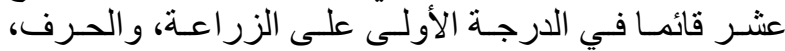

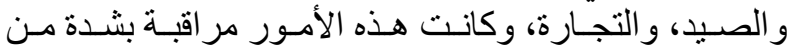

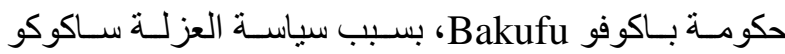

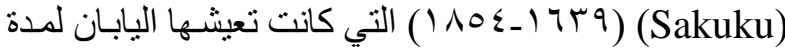

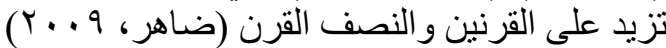

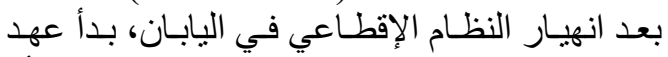

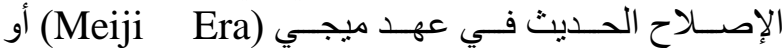
(MeijiRestoration)

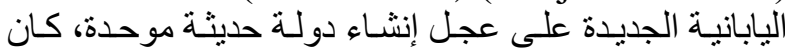

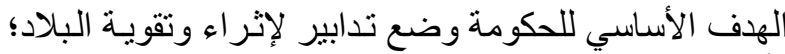

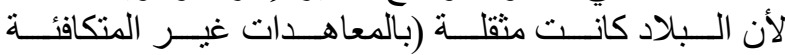
(Unequalled Treaties

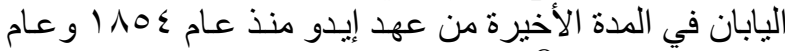

( Ono ,1996). 1101

يتفق البـاحثون المتخصصـون في دراسـة النطـور

الاقتصـادي لليابـان على تقسيم النمو الاقتصـادي على ثلـلاث

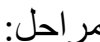

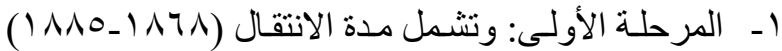

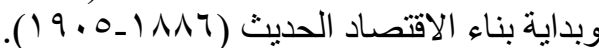

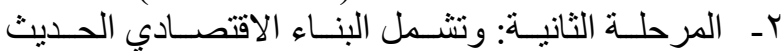

.(190r-19.0)

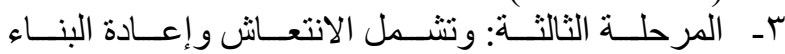
الاقتصادي الحديث بعد الحرب العالمية الثانية وتمتد إلى الى الى 


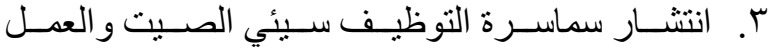

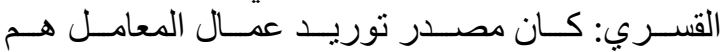

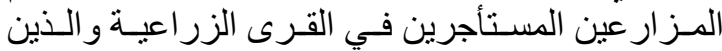

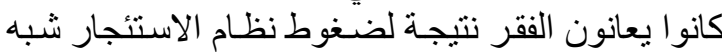

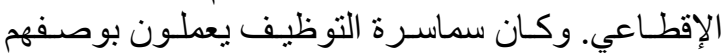

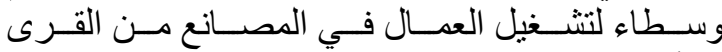

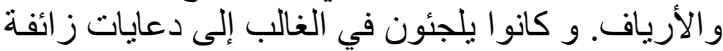

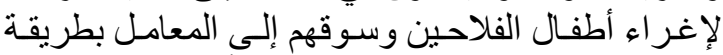

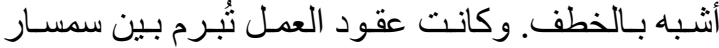
التوظيف ورب العائلة الزراعية المعنية.

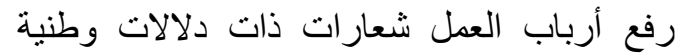

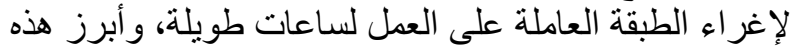

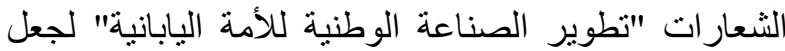

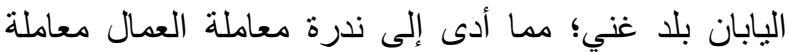

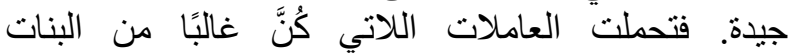

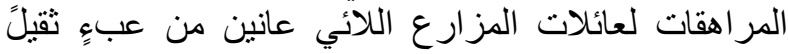

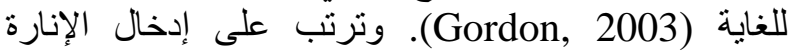
الكهربائية في اليابان في السبعينيات والثمانينيات الكيات من القرن الانارن

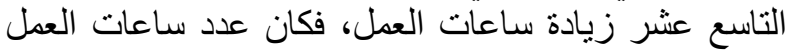

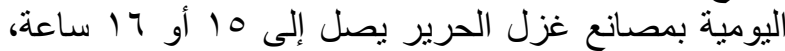

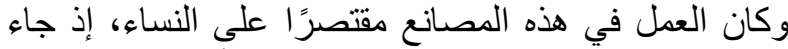

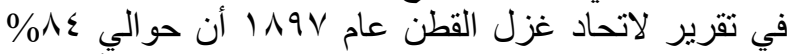

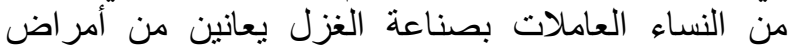

المهنة ومن الإصابات المهنية (حامد، العاءل 997 (1) ).

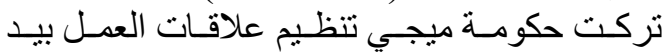

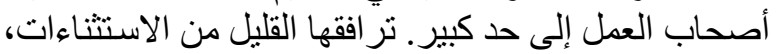

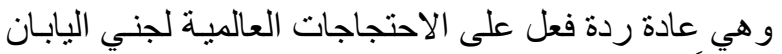

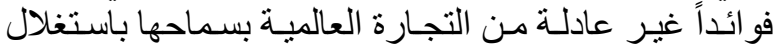

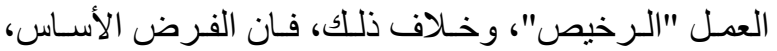

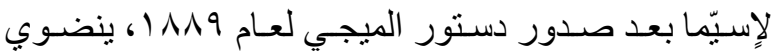

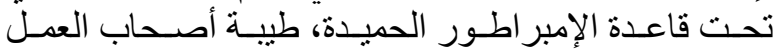

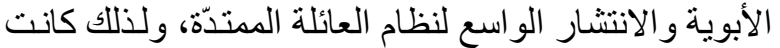

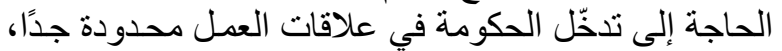

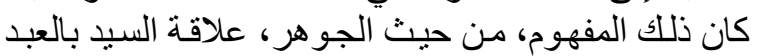

.(Levine, 1983)

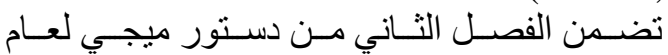

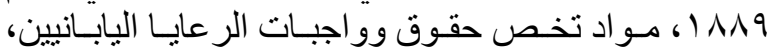

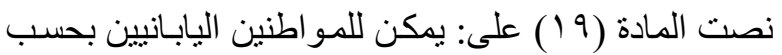

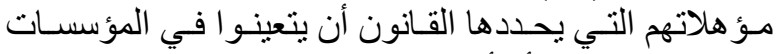

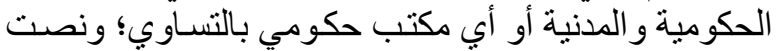

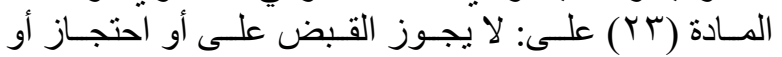

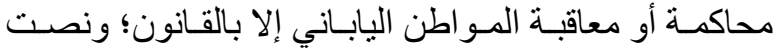

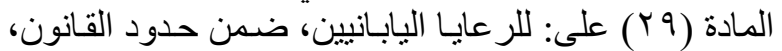

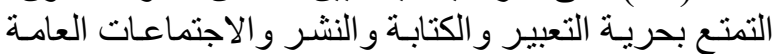
و الانتماء للجمعيات (Kodansha, 1983). وتضمن الفصل الثاني أيضا من دستور ميجي على الئى

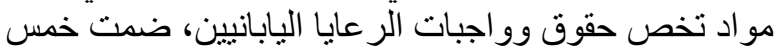

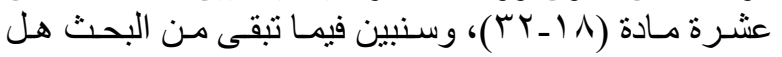

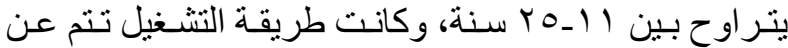
طريق سماسرة يقنعون أولياء الفتيات بالعمل بتنظيم عقد أمده

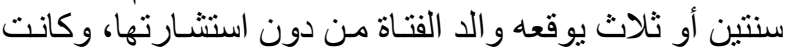

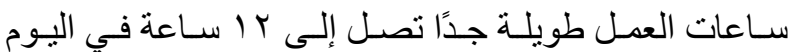

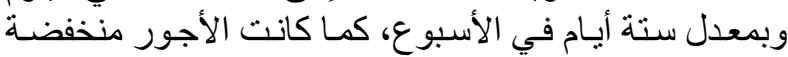
جدًا تصل إلى • †\% من أجور الرجال (Nafzige, 2016)

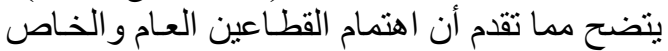

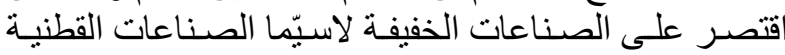

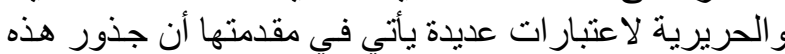

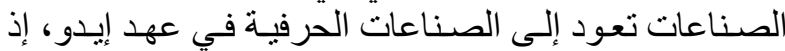

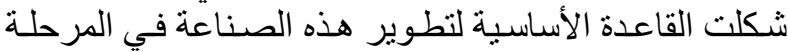

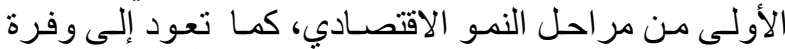

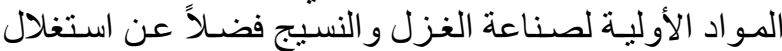

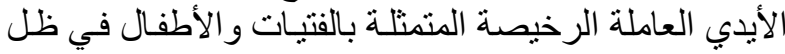

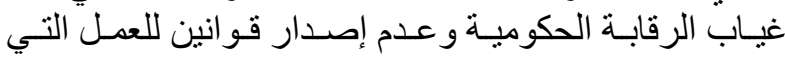

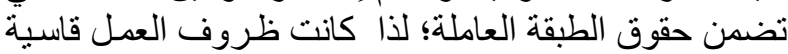

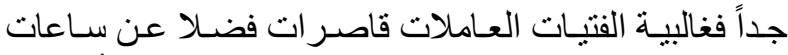

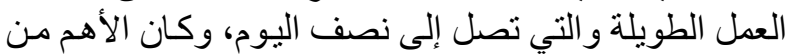
ذلك أن غالبية أجور عمل الفتيات تذهب الفي إلى الإبـاء بموجب الاهب عقود العمل المبرمة سلفًا بينهم و أصحاب المّاب المصانع.

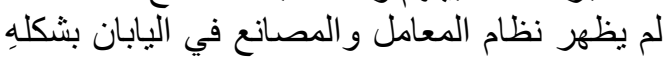

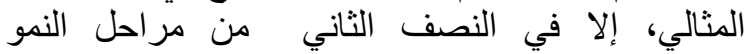

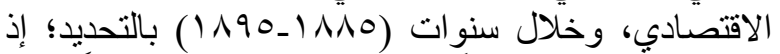

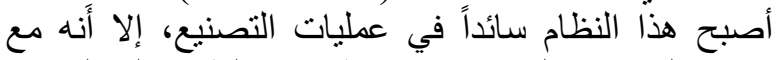

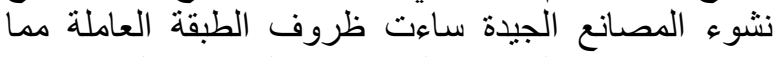

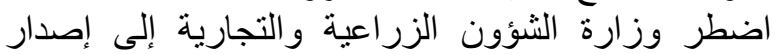

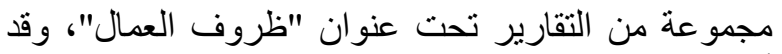

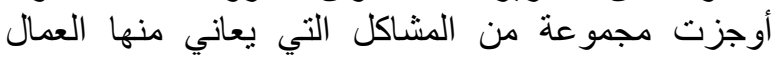

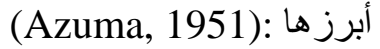

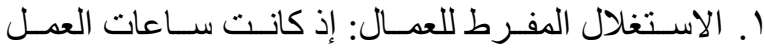

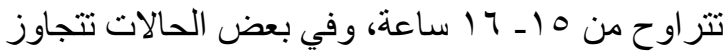

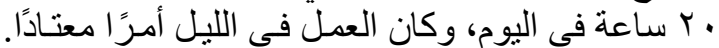

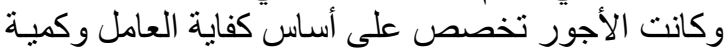
الإنتاج، فكان من لا يصل إلى مستوى الكفايـة المعياري الكياري

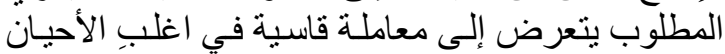

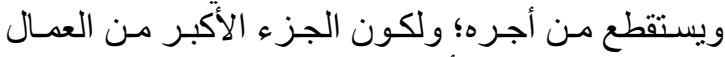

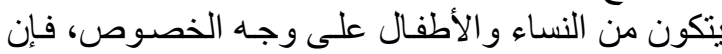
العمل المفرط نتج عنه المزيد من الظروف التهاء التي يؤسف فئ

r. كثرة الحو ادث في المعامل: شيوع الحوادث في المعامل

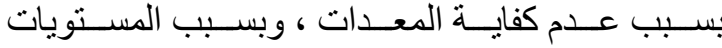

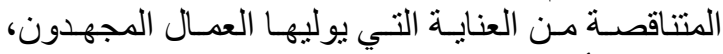

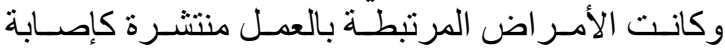

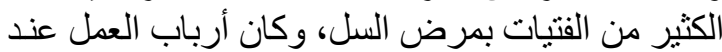

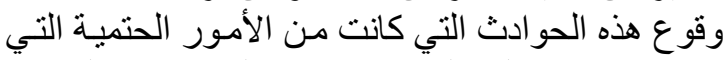

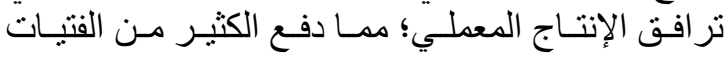

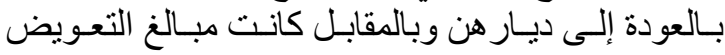




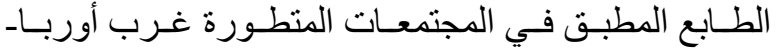

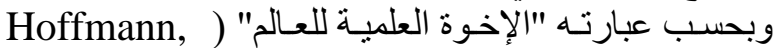

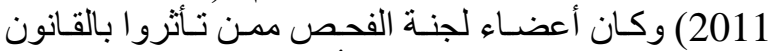

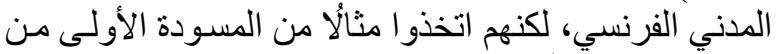

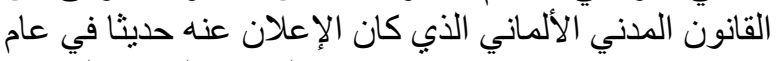
(Hiroshi, 1983)؛ IANV

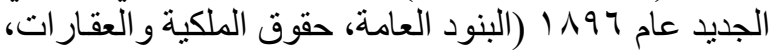

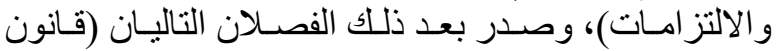

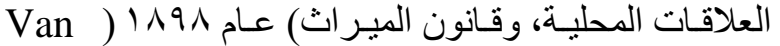

(Den Berg, 2018

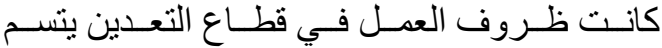

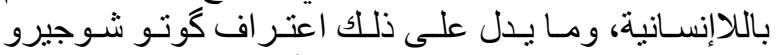

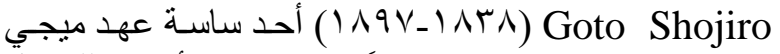

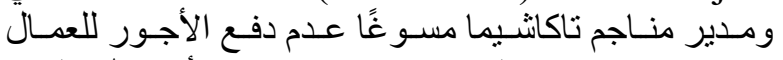

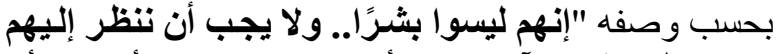

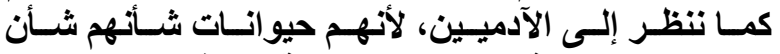

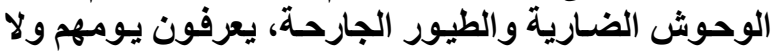

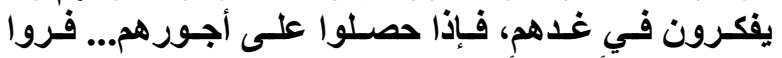
الواحد تلو الأخر، وأصاب الكساد منـاجم تاكاثشيما" (حامدا،

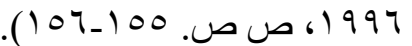

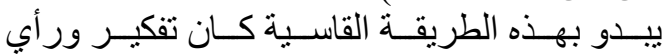
السياسيين اليابانيين الذين يقون ور اء الطياء الإمبر اطور ميجي في

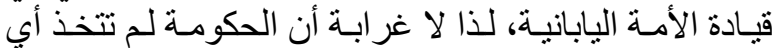

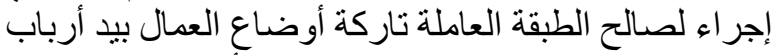

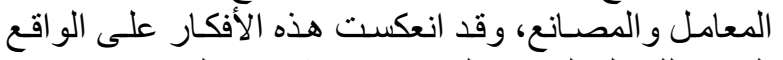

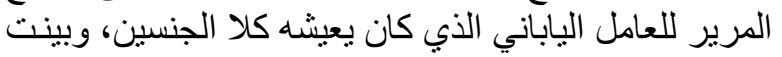

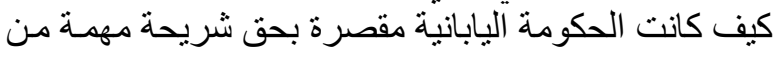

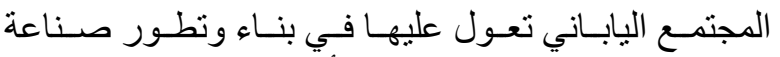

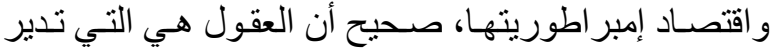

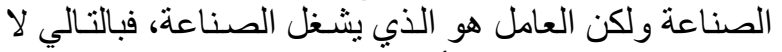
يقل دور العامل عن دور أرباب العمل و المهندسين.

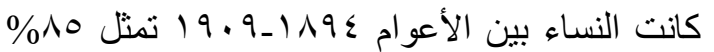

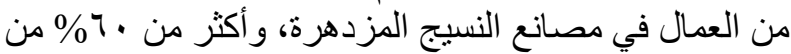

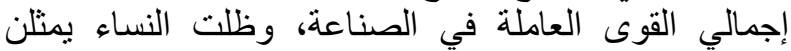
غالبية القوى العاملة الصناعية في عقد ثلاثينيات القرن (Nafzige, 2016)

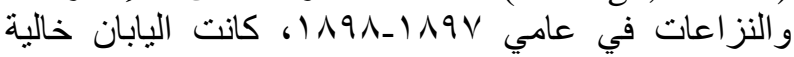
نسبيًا من الإضرابات في عهد ميجي، كما مبين في الجدول ليانيان

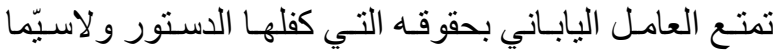

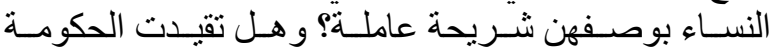

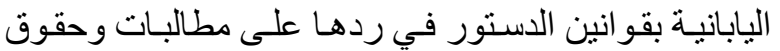
العمـال في تنظيم النقابـات و المطالبـة بحقوقهم عن طريق فيق

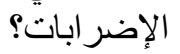

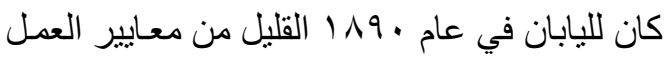

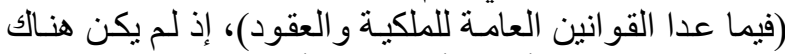

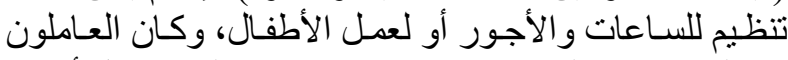

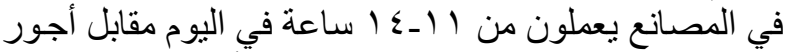

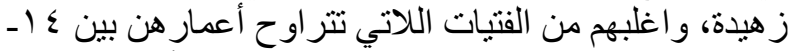

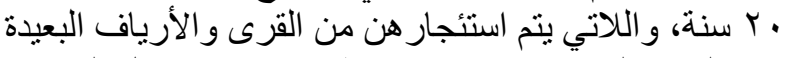

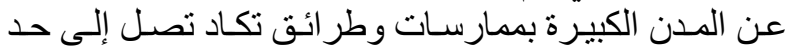

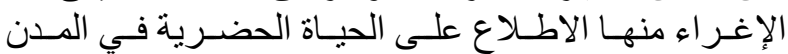

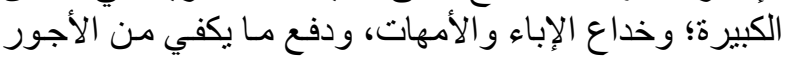

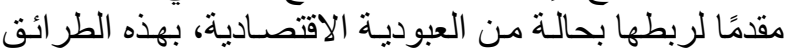

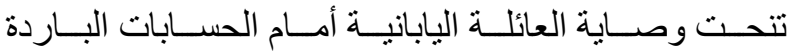

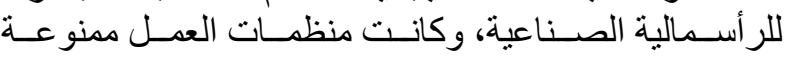
.(Nafzige, 2016)

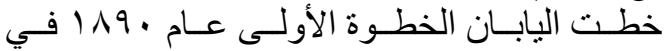
مشروع سن القانون المدني الذي تر أسـه الفرنسي غوست غوستاف

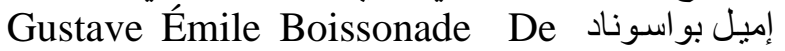
القيأن Fontarabie

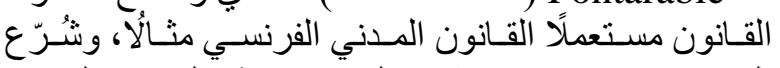

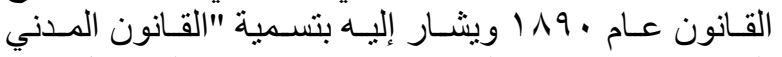

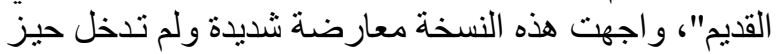

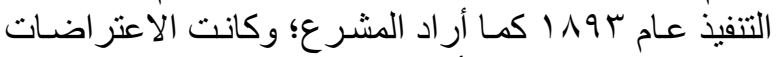

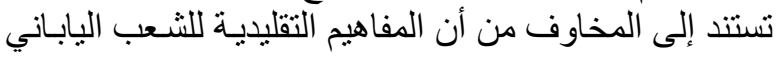

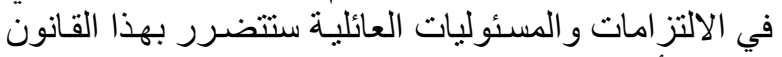

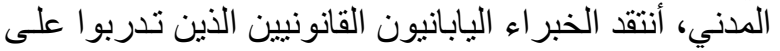

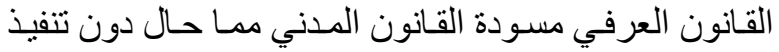

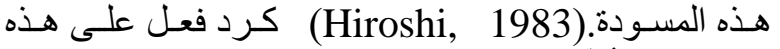

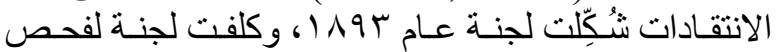

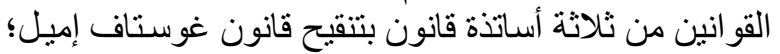

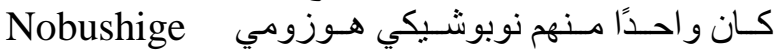
الإمبر Hozumi

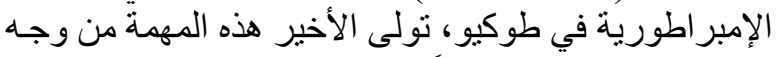

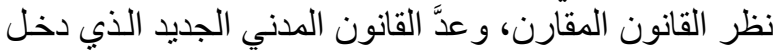

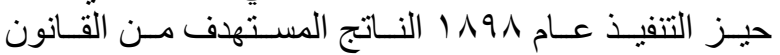

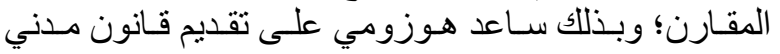
مدون حديث للحكومـة اليابانيـة على سياق القـانون الدولي 
December 29, 2021 [Vol. 32(4)]

P-ISSN: 1680-8738; E-ISSN: 2663-547X

\begin{tabular}{|c|c|c|c|c|c|}
\hline الإضر ابات & النز اعات & السنة & الإضر ابات & النزاعات & السنة \\
\hline v & $1 T$ & $1 \wedge 94$ & · & $r$ & $1 \wedge V$. \\
\hline 7 & V & $119 \leq$ & . & 1 & $|\wedge V|$ \\
\hline V & 11 & 11990 & . & r & INVY \\
\hline $1 \leq$ & ro & 1197 & · & 1 & IAVT \\
\hline$\wedge 1$ & 114 & $1 \wedge 9 V$ & · & . & $1 \wedge V \varepsilon$ \\
\hline$\varepsilon$ & or & $1 \wedge 91$ & . & · & IAvo \\
\hline 19 & $r \leq$ & 1199 & . & . & $1 \wedge \vee 7$ \\
\hline rr & rv & $19 \ldots$ & . & 1 & IAVV \\
\hline 17 & $r T$ & 19.1 & · & $r$ & $1 \wedge \vee \wedge$ \\
\hline IV & $r \wedge$ & $19 . r$ & · & . & $1 \wedge \vee 9$ \\
\hline$r t$ & $\leqslant 1$ & $19 . r$ & . & $r$ & $1 \wedge \Lambda$. \\
\hline$\wedge$ & 1. & 19.5 & . & r & $|\wedge \lambda|$ \\
\hline rr & $r$. & 19.0 & 1 & v & IANT \\
\hline Tr & T & 19.7 & · & $r$ & IANT \\
\hline $1 T \leq$ & $r r \leq$ & $19 \cdot v$ & $\cdot$ & 1 & $1 \wedge \wedge \varepsilon$ \\
\hline $7 \varepsilon$ & 90 & 19.1 & 1 & 0 & 1110 \\
\hline 10 & $\varepsilon$ & 19.9 & 7 & $\wedge$ & $1 \wedge N T$ \\
\hline r & $\leqslant 9$ & 191. & 1 & r & IANV \\
\hline rq & $\leqslant 9$ & 1911 & 0 & IT & $1 \wedge \wedge \wedge$ \\
\hline$\varepsilon \varepsilon$ & vo & $191 r$ & 1. & IV & 1119 \\
\hline IV & $r \wedge$ & $191 \pi$ & 0 & 9 & 119. \\
\hline \multirow[t]{2}{*}{11} & rV & $191 \leq$ & $\wedge$ & Ir & $1 \wedge 91$ \\
\hline & & & V & IV & 1194 \\
\hline
\end{tabular}

(Nimura,1990): ينظر

فعالية قانون شرطة السلام العام (Chian Keistatsu Ho)

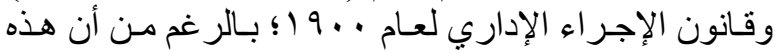

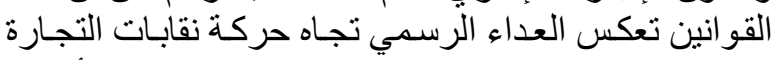

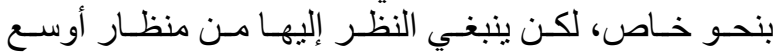

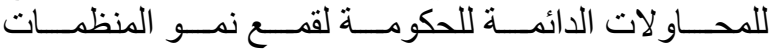

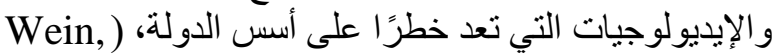

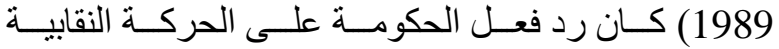
و الإضر ابات المرتبطة بها هو سن قانون شرطة السلام العام

.(Harari, 1973)

خالفت حكومة ميجي بهذه الإجر اءات مو اد دستور

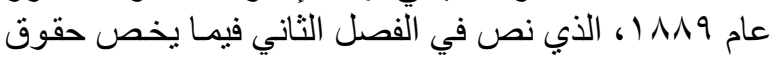

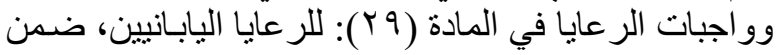

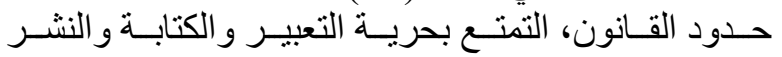

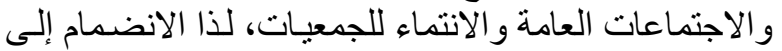

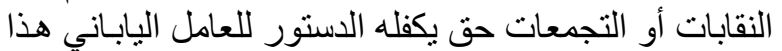

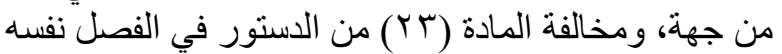

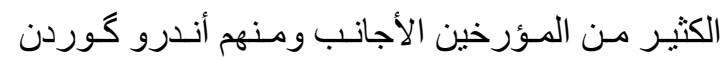

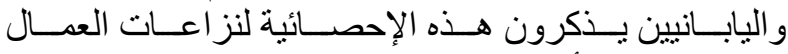

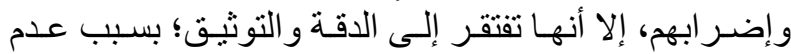

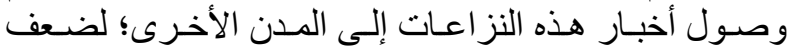

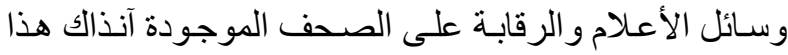

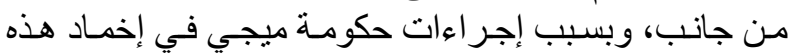
النزاعات و الإضـر ابات بـالقوة و التدخل العسكري في بعض إن إن

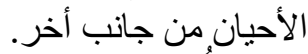

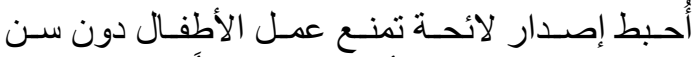

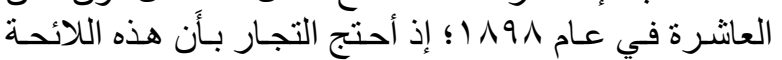

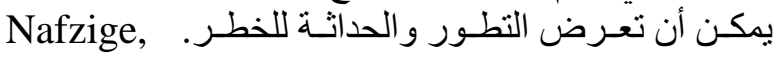

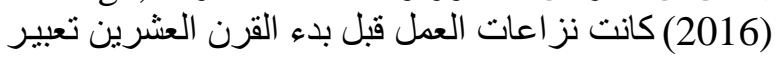

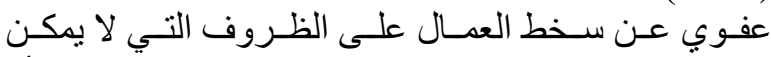

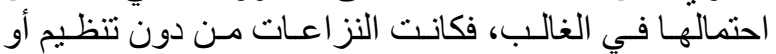

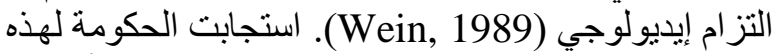

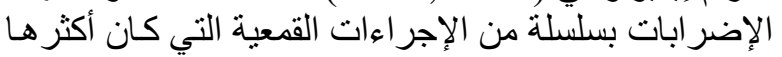




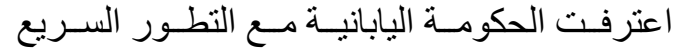

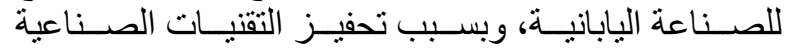

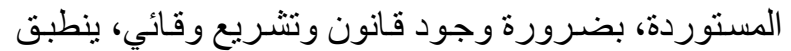

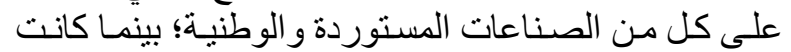

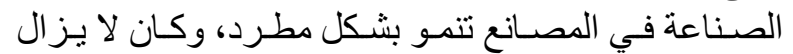

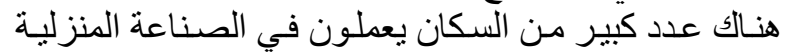
وفي الزراعة في الوقت نفسه، ويشكلون مجمو عة فئن كبيرة من

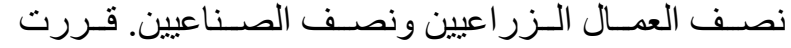

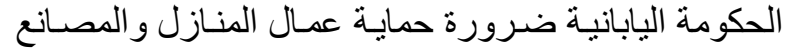

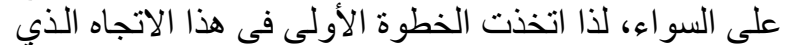

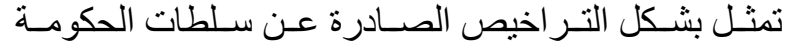

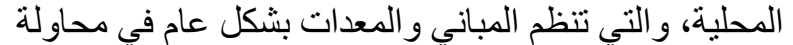

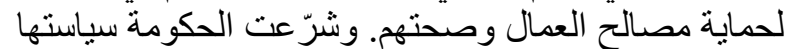
الخاصة بحماية العمال، على غر ار سياسـة الدول الأجنبية، بموجب قانون شـامل صـادر عن الهيئة التشريعية الوطنية الإنية

(Matsuoka, 1931)

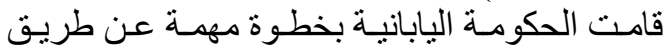

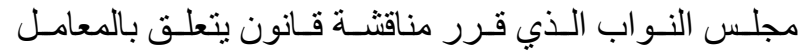

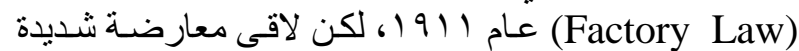

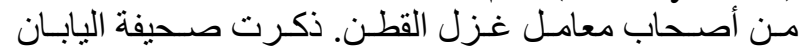

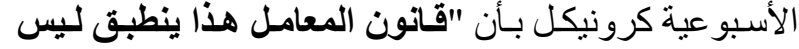

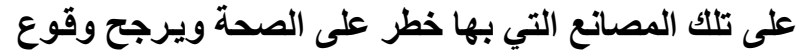

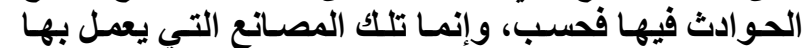

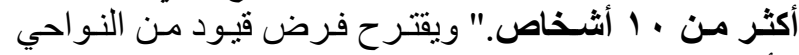

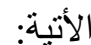

1 ـ تشغيل الأطفال من الذكور و الإناث دون سن ع ا سنة؛

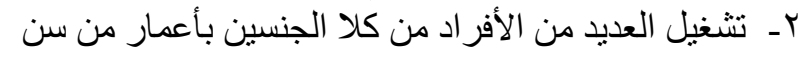

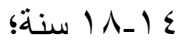

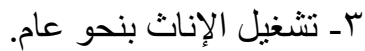

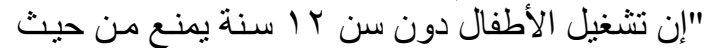

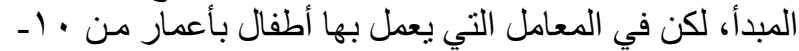

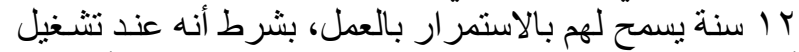

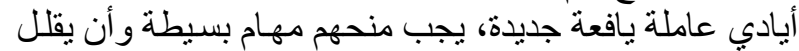

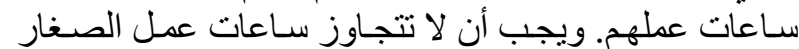

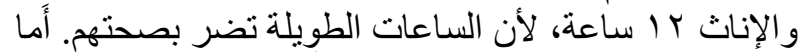

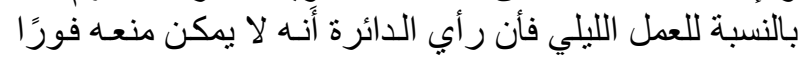

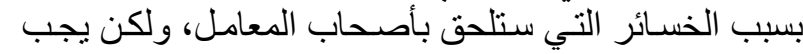

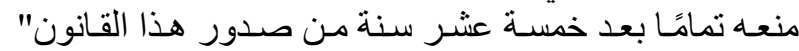
. (Argus, 1911)

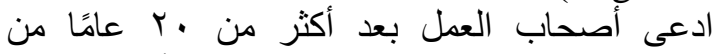

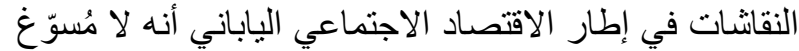

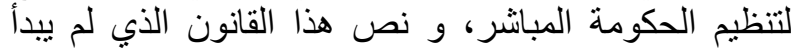

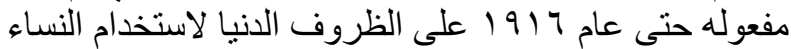

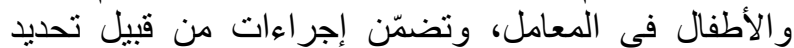

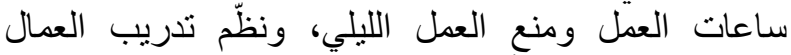

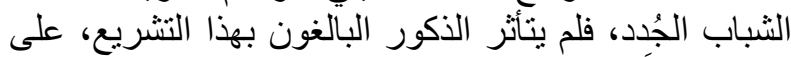
الرغم من أَنه في تسعينيات القرن التاسع عشر ، تبنوا تشريع على التُع
الذي نص: لا يجوز إلقاء القبض أو احتجاز أو محاكمـة أو

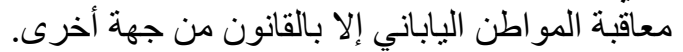

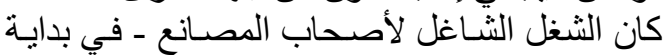

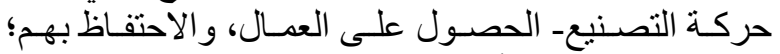

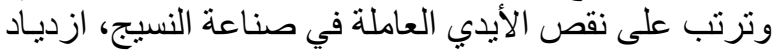

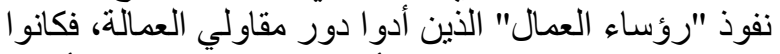

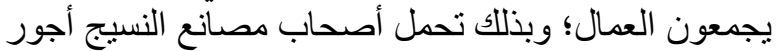

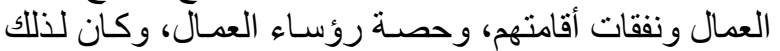

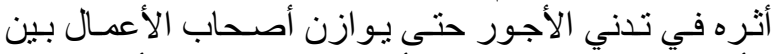

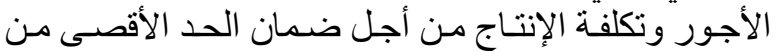

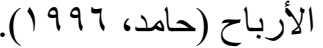

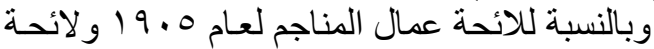

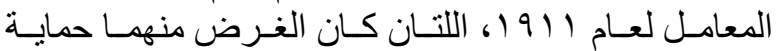

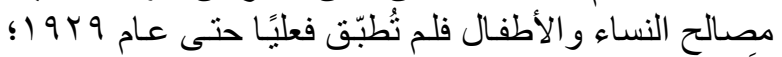

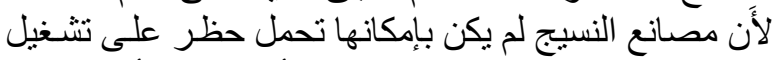
ارخص يد عاملة منوفرة - النساء و الأطفال- في أثناء العمل الليلي (Nafzige, 2016).

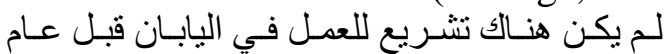

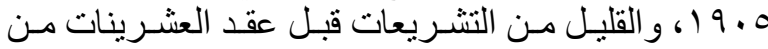

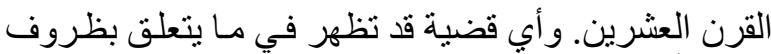

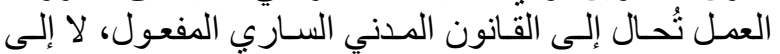

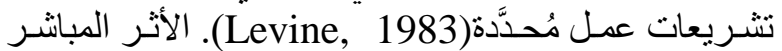

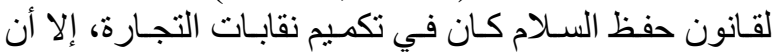

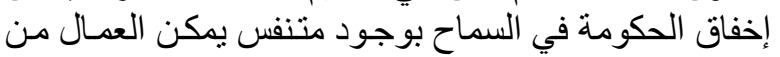

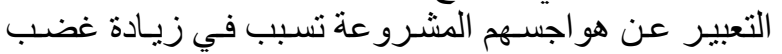

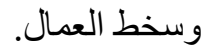
التحليل التفصيلي للنز اعـات و الإضـر ابات العمالية

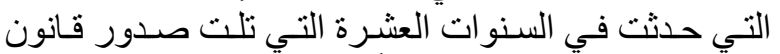

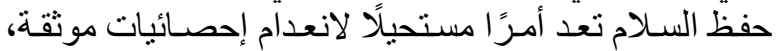

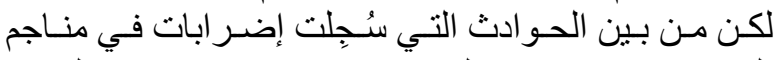

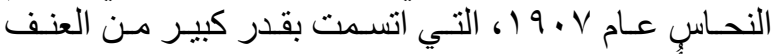

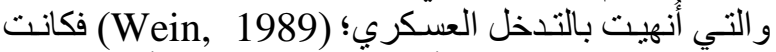

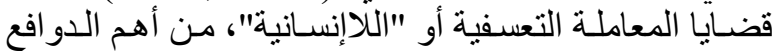

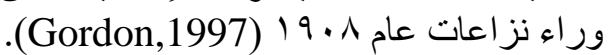

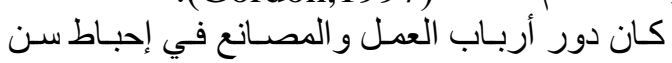

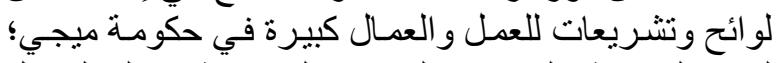

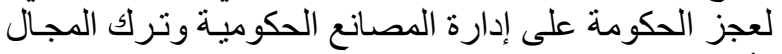

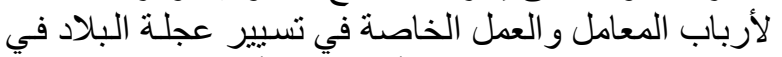

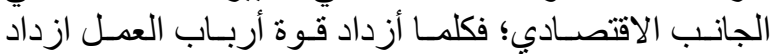

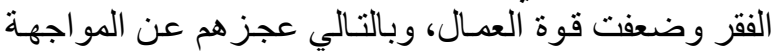
وتحقيق مطالبهه.

على الرغم من أن بعض ممارسـات العمل كعمـال

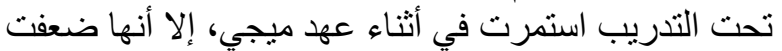

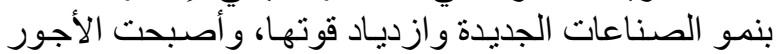

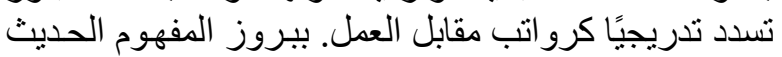

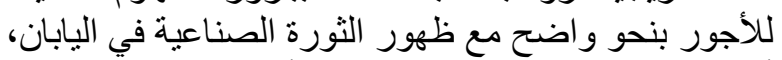

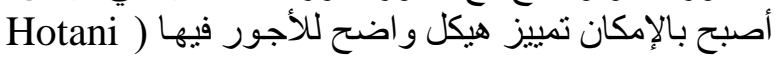

.(\& Hayashi,1961 


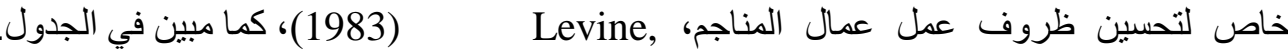
جدول r

\begin{tabular}{|c|c|c|c|c|c|c|c|c|c|c|c|c|}
\hline$\%$ & المعادن & $\%$ & النسيج & $\%$ & العمال & $\%$ & الحرفيين & $\%$ & المناجم & الإضر ابات & نزاعل & السنة \\
\hline$\cdot, \cdot$ & $\cdot$ & $\cdot, \cdot$ & $\cdot$ & $\cdot, \cdot$ & . & $r \wedge, \nearrow$ & $r$ & $V 1, \varepsilon$ & 0 & . & v & $V \varepsilon_{-} / A V$. \\
\hline$\cdot, \cdot$ & . & $\cdot, \cdot$ & . & $\cdot$, & . & $r_{0},$. & 1 & vo,. & r & . & $\varepsilon$ & vQ_। $\wedge V_{0}$ \\
\hline$\cdot, \cdot$ & . & $\cdot, \cdot$ & . & $1 \wedge, \lambda$ & $r$ & $7, r$ & 1 & $0 .,$. & $\wedge$ & 1 & 17 & $\Lambda \varepsilon_{-} \mid \wedge \lambda$. \\
\hline$r, r$ & 1 & ro,. & 11 & $11, \varepsilon$ & 0 & $7, \lambda$ & $r$ & $r_{0},$. & 11 & r & $\varepsilon \varepsilon$ & $19_{-} 1110$ \\
\hline $1, v$ & 1 & $r_{0, q}$ & 10 & $\mid r, 1$ & v & KY, & r & $\mid r, \lambda$ & $\wedge$ & rr & 01 & $9 \varepsilon_{-} 1 \wedge 9$. \\
\hline$V, r$ & IV & $\Lambda, 0$ & $r$. & 17,7 & rq & $r \Lambda, 1$ & 74 & $V, r$ & IV & 171 & rro & $9 \Lambda_{-} 1190$ \\
\hline$\Lambda, 0$ & ir & $1 \leqslant, 1$ & $r$. & $\Lambda, 0$ & Ir & 19,1 & rA & $v, v$ & 11 & 19 & $1 \leqslant r$ &.$\varepsilon_{-1} 19 \ldots$ \\
\hline $1 ., 1$ & $\varepsilon \varepsilon$ & $7, V$ & rq & $10, r$ & 74 & $i v, 0$ & VI & 17,1 & $v$. & rov & $\varepsilon r_{0}$ & $.9-19.0$ \\
\hline $1 ., 9$ & rT & $1 \cdot, 9$ & rT & $r, r$ & or & $17, \varepsilon$ & rq & 0,9 & $1 \varepsilon$ & 101 & rri & $\mid\left\{\varepsilon_{-}|9|\right.$. \\
\hline$\wedge, 7$ & 1.1 & $1 \cdot, r$ & $|r|$ & $10, V$ & 110 & $19, \varepsilon$ & rrq & $I_{1}, 0$ & $1 \leqslant V$ & vol & $11 \times 9$ & الدجموع \\
\hline$\Lambda, \varepsilon$ & $r, r$ & $1 \cdot, r$ & $r, r$ & 10,7 & $\varepsilon, 1$ & 19,1 & $0,$. & $\mid r, T$ & $r, r$ & 10,9 & $r T, r$ & - ـ معدل السنة \\
\hline
\end{tabular}

ينظر: (Nimura, 1990)

لنمـو إمبر اطوريـة تجاريـة متناميـة وزيـادة تـأثثر الزايباتسـو (Zaibatsu)

(Nafzige, 2016)

تطورت اليابان لتصبح الدولة الصناعية الوحيدة في

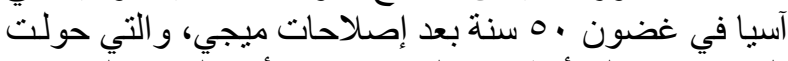

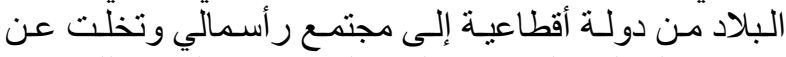

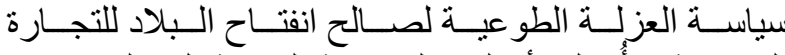

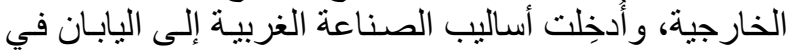

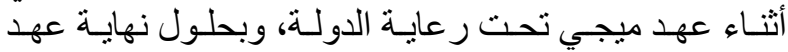

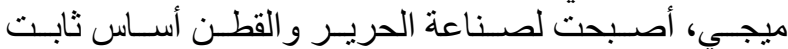

.(Hotani, Hayashi, 1961)

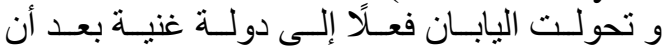

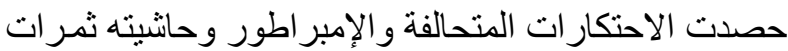

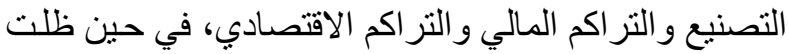

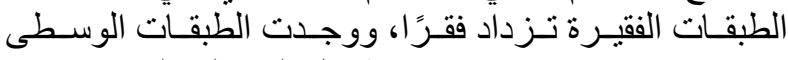

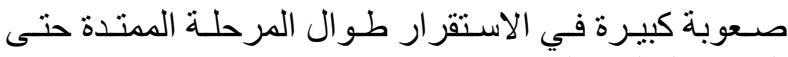

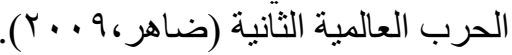

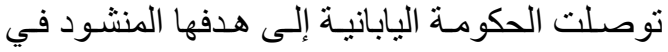

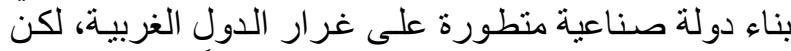

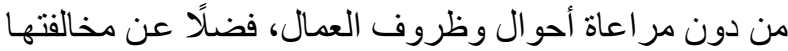

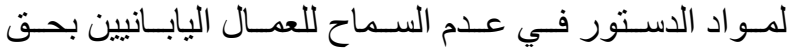

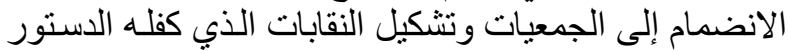

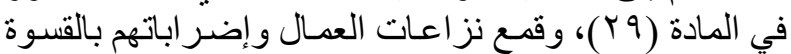

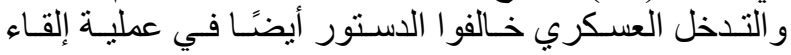

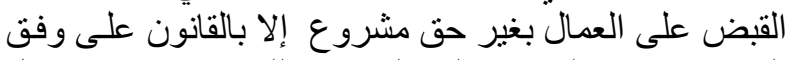

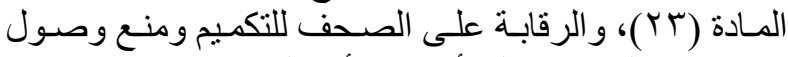

صدى هذه النزاعات إلى أرجاء الأمة المة اليابانية.

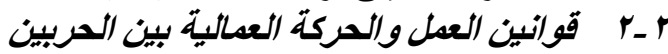

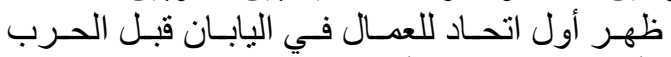

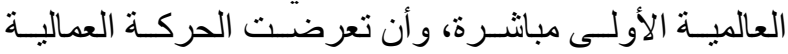

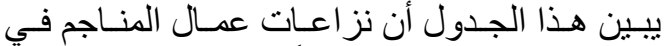

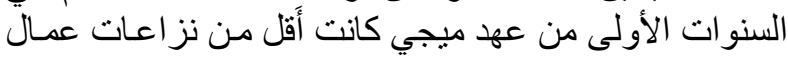

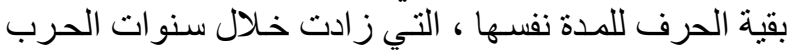

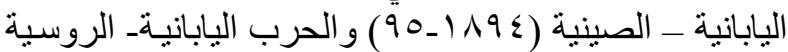

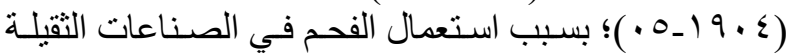

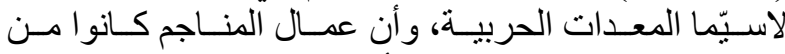

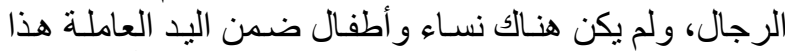

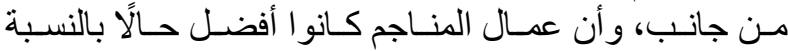

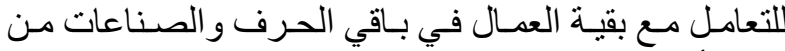

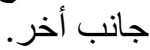

كانت العاملة المثالية في أواخر عهد ميجي تهجر

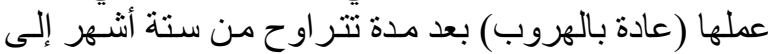

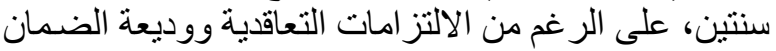

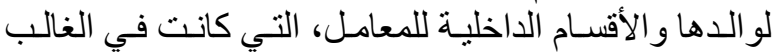

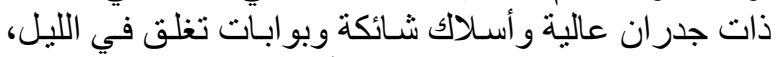

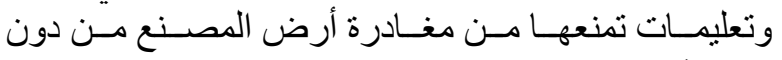

رخصة (Nafzige, 2016).

تسبيت إصـاحات ميجـي بانهيـار الحرفـة كـالغزل

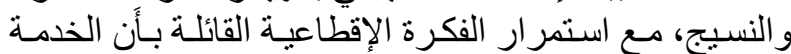

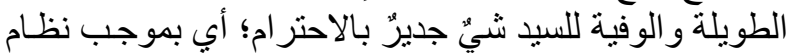

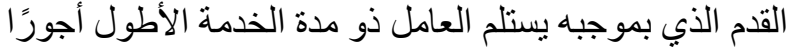

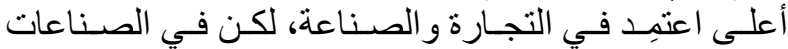

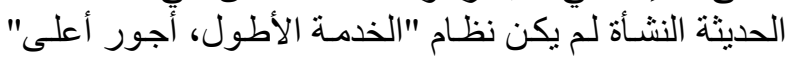

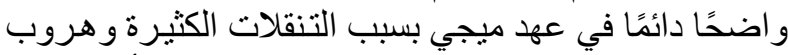

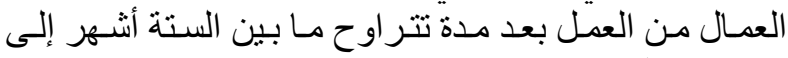

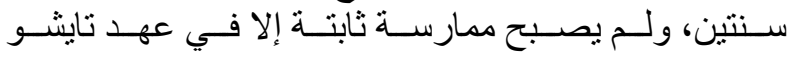

.(Hotani, \& Hayashi,1961)

تركت الحكومـة لأربـاب العمل الحريـة في اختيـار

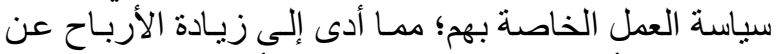
طريق دفع أجور قليلة؛ وكانت هذه الأربـاح مصدرًا مهمًا 


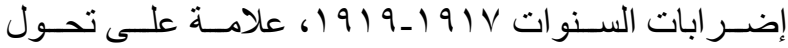

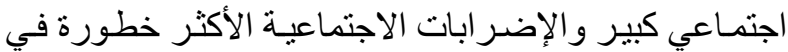

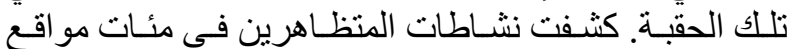

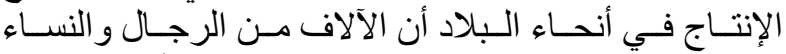

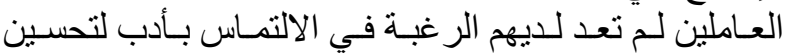
ظروفهم (Gordon, 2018).

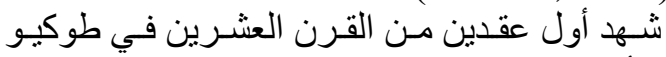

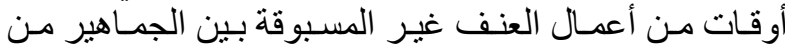

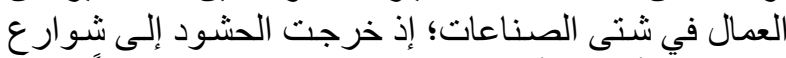

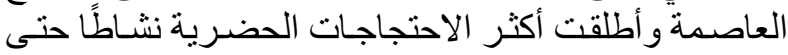

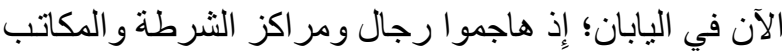

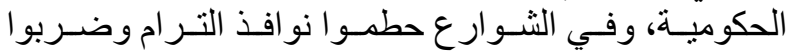

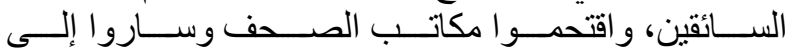

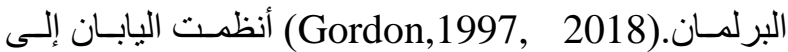

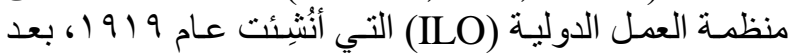

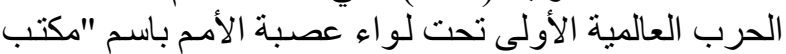

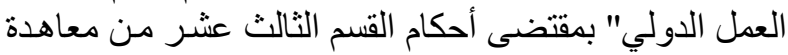

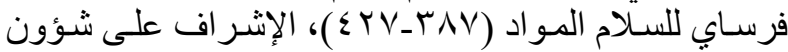

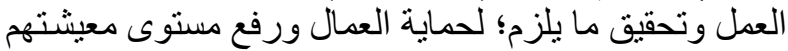
في جميع أنحاء العالم. Maul, 2012) أمـا بالنسبة للفيلاحين

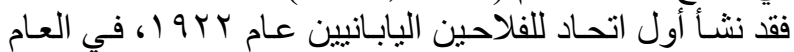

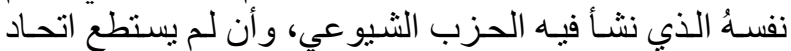

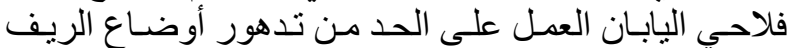

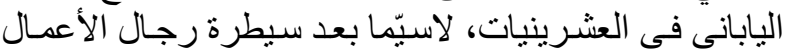

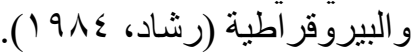

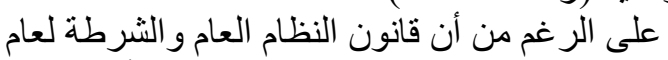

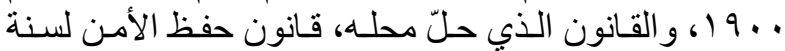

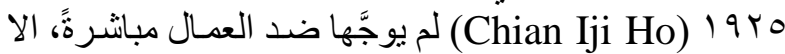

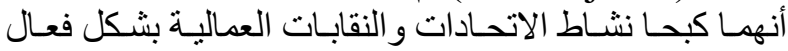

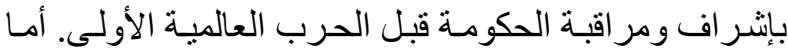

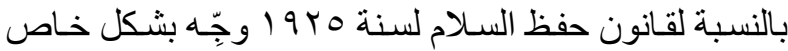

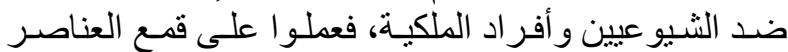

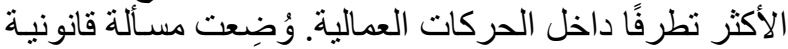

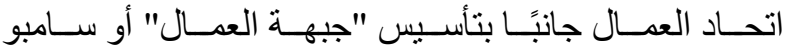

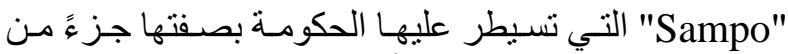

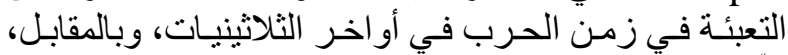

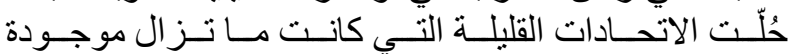

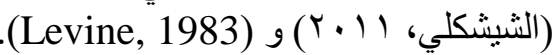

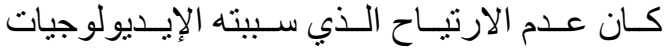

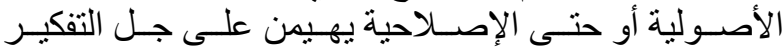

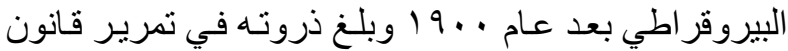

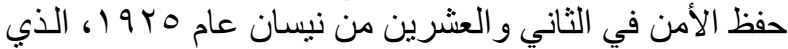

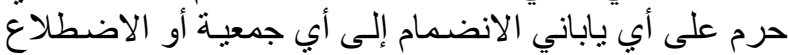

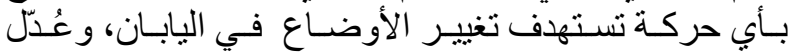

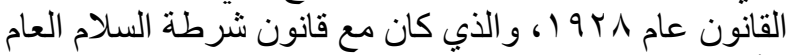

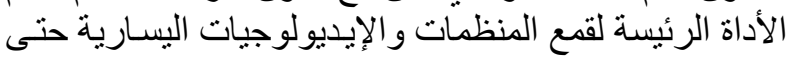

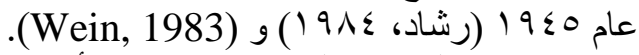

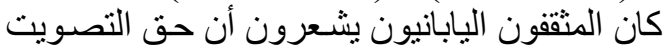

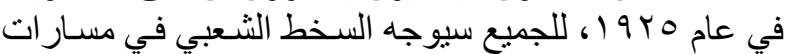

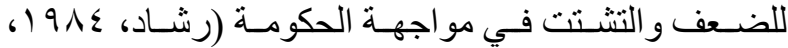

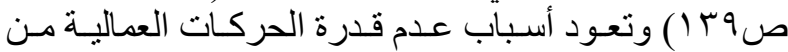

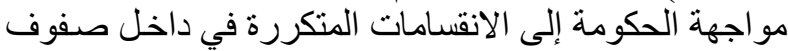

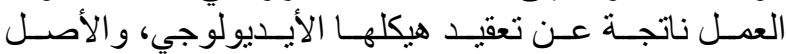

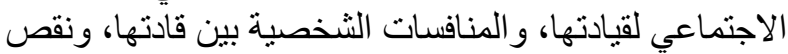

وسلاسة الدعم بين الجمهور (Harari,1973).

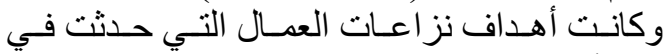

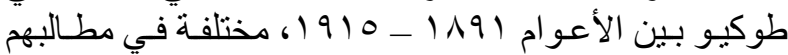

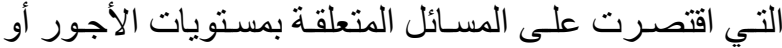

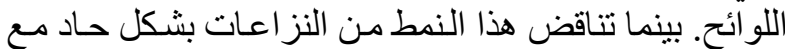

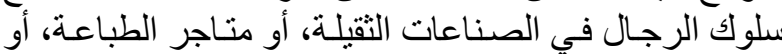

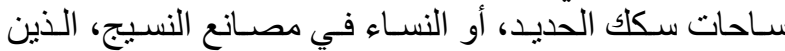

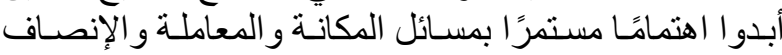

.(Gordon, 1997)

تغيرت حركة العمـال اليابانيـة بنحو مثير للاهنمام

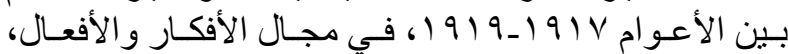

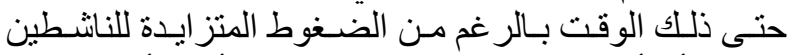

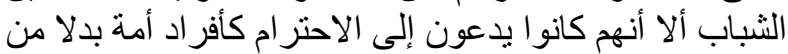

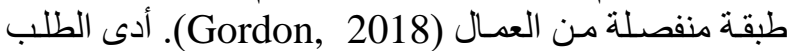

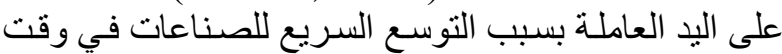

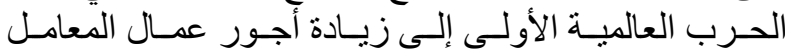

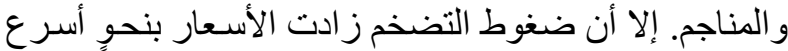

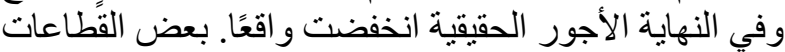

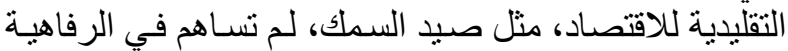

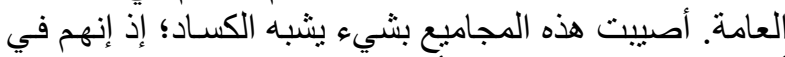

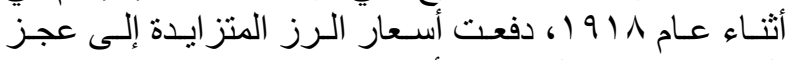

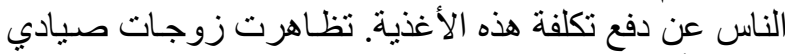

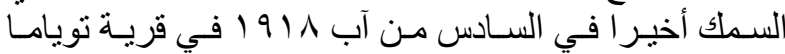

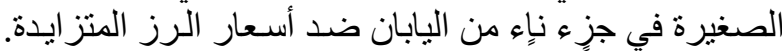

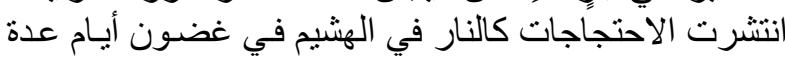

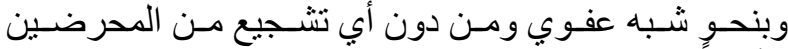

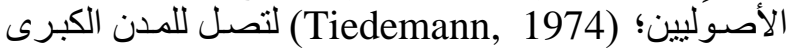

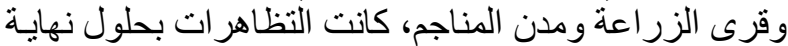

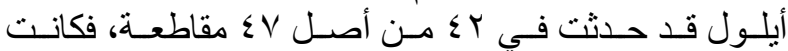

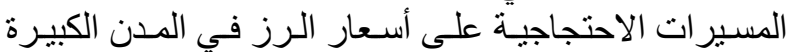

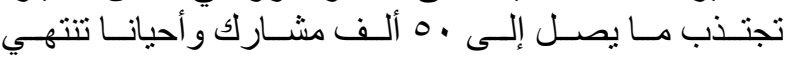

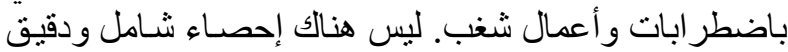

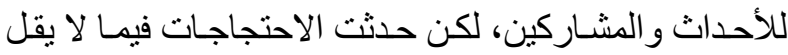

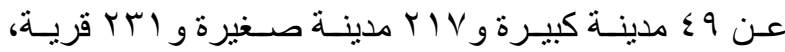
بمشاركة . . ألف متظـاهر و وعلى الأرجح أن الرقم تجاوز

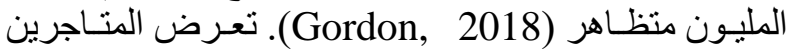

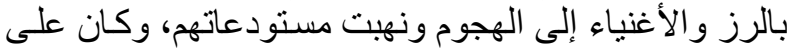

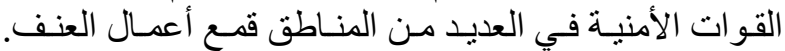

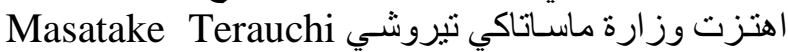

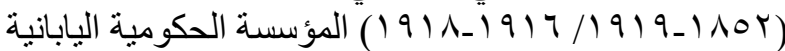

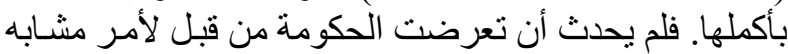

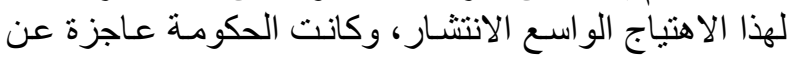

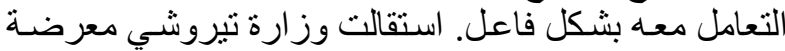

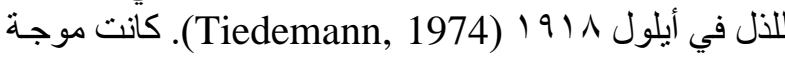




\section{r r r r تشريعات العدل في ظل الاحتلال الأمريكي لليابان (190r-19:0)}

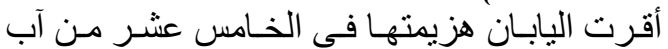

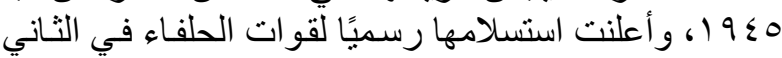

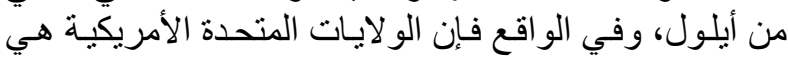

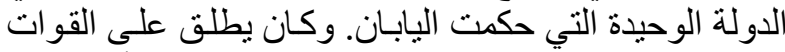

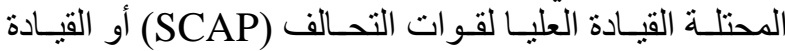

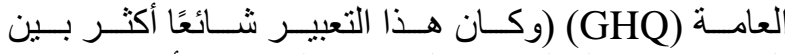

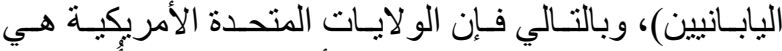

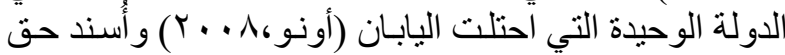

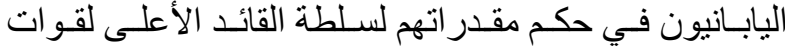

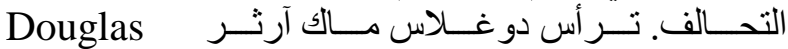

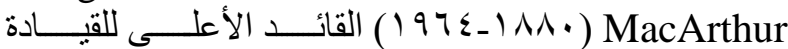

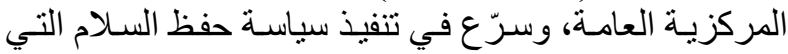

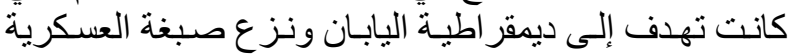

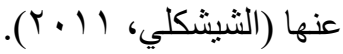

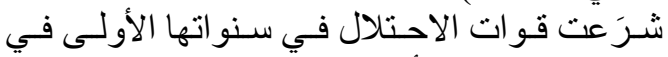

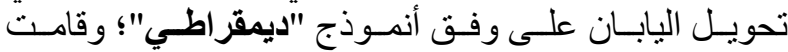

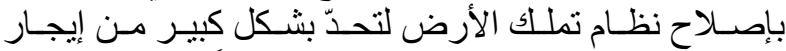

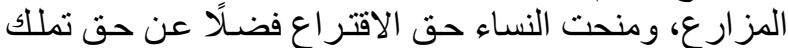

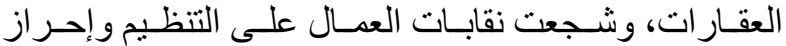

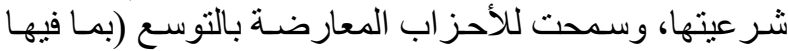

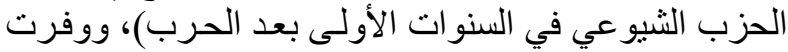

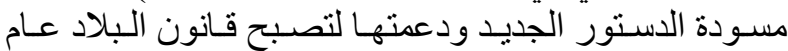

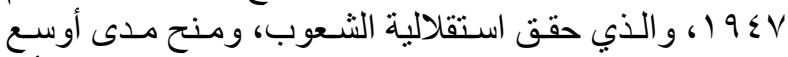

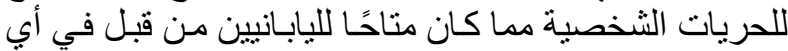

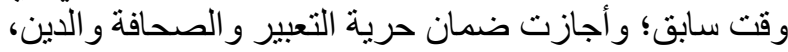

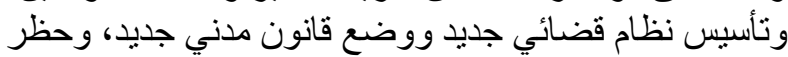

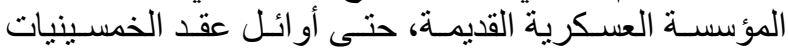

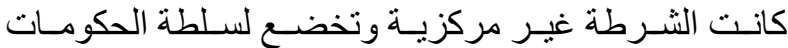

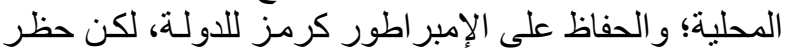

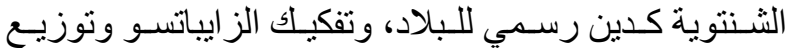
ممتلكاتهم (Tiedemann, 1974). جعلت سلطات الاحتلال

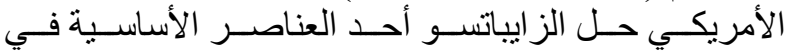

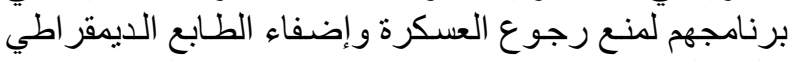

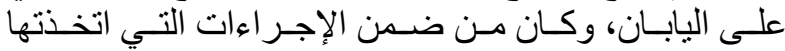

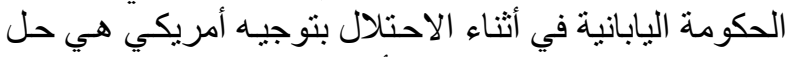

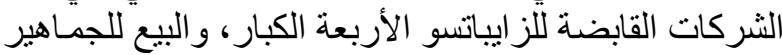

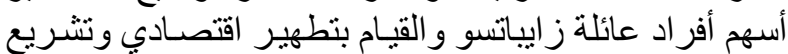

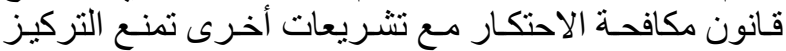

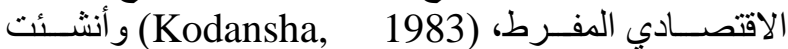

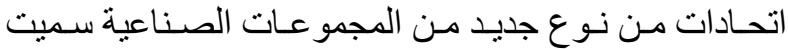

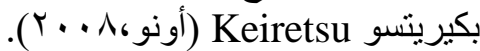

تركزت نشاطات القيادة العليـا لقوات الحوناء الحلفاء خـلال

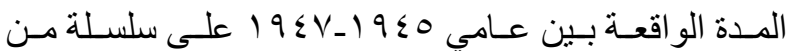

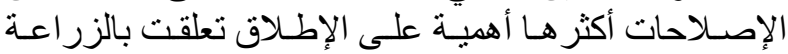

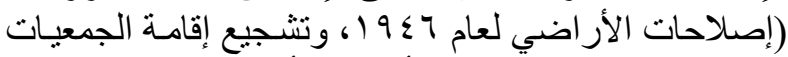

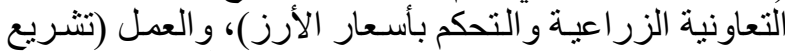

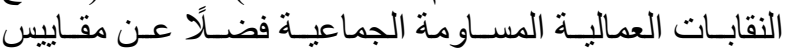

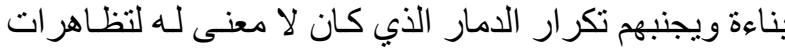

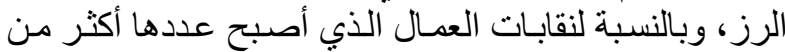

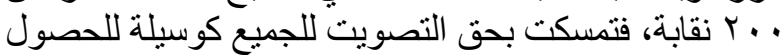

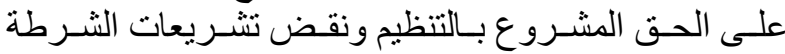

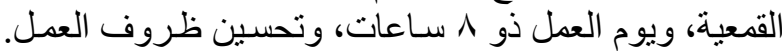

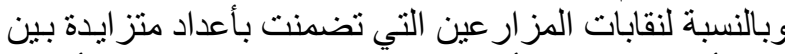

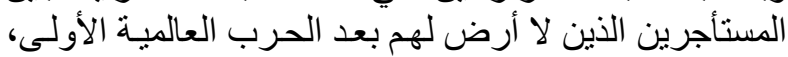

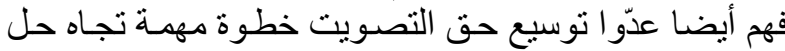
مشاكلهم الاقتصادية (Tiedemann, 1974). حدث تطورًا من الحكومة اليابانية في كيفية التعامل

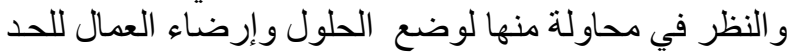

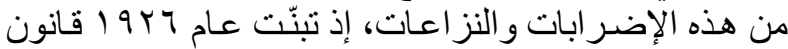

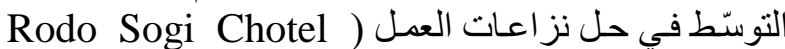

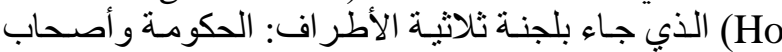

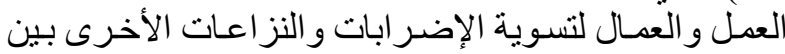

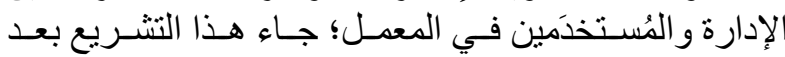

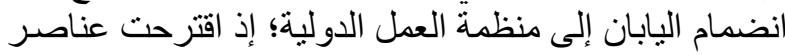

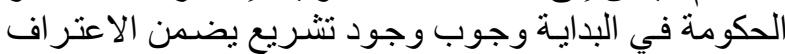

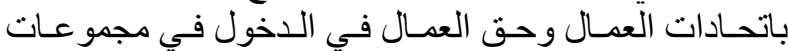

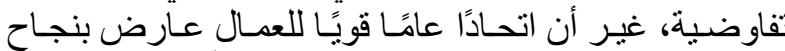

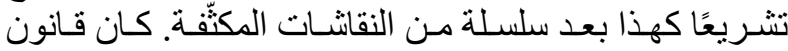

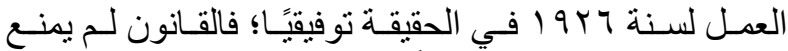
الاتحادات؛ لكنه لم بمنحها حقًا قانونيًا بالتنظيم و الاعتر اف بهاء

(Levine, 1983) اكتسـبت النقابـات اليابانيــة القـوة الاقتصــادية مـن

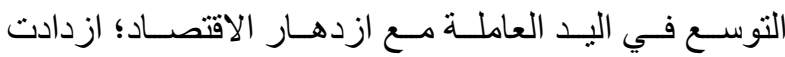
الدعامات، وسـاعدت القوة الاقتصـادية المتز ايدة للنقابـات في الإني

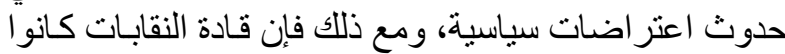

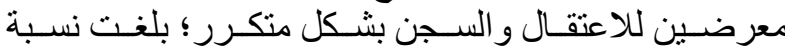

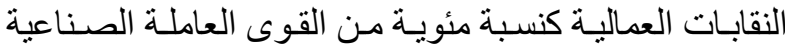

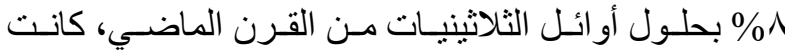

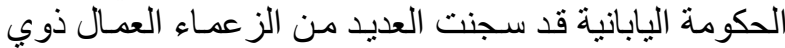

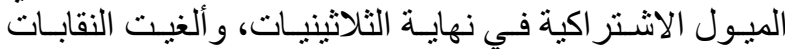

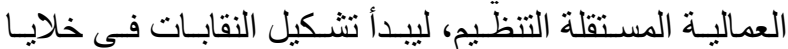

سياسية تابعة للمصانع بحلول عام • ـ 19 (Bird, 2005). كانت قو انين العمل الأخرى ذات العات الأهمية في ما قبل العبل

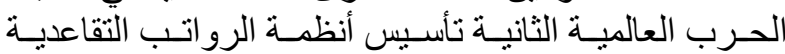

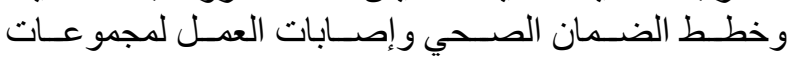

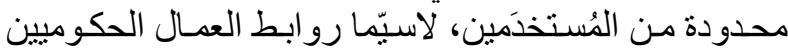

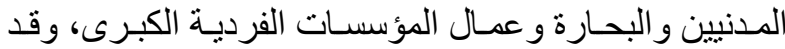

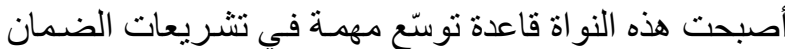

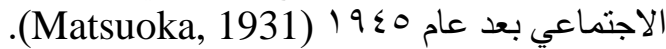

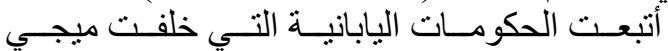

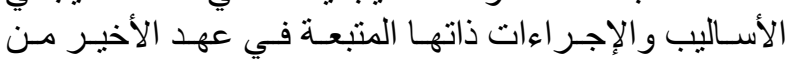

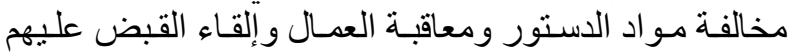

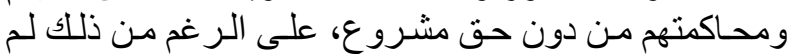

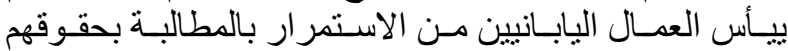

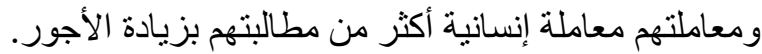


7 ـ 9 1، وكان العمال في أثناء الحرب منظمين في منظمـات

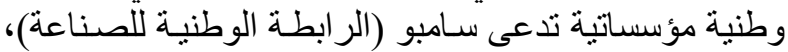

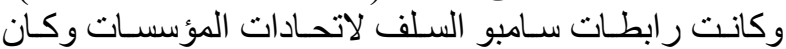

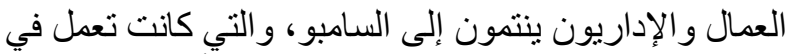

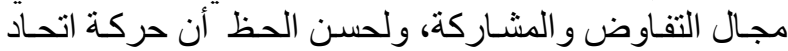

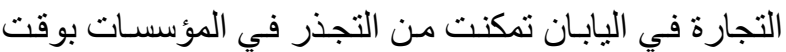

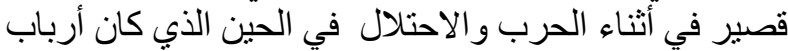

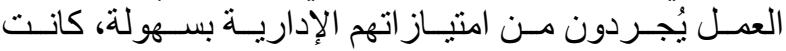
اتحادات المؤسسات إحدى "أطفال الحرب" الإدارئ (Bird, 2005). منح قانون اتحادات العمل الذي أصبح ساري العاب المفعول

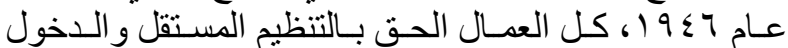

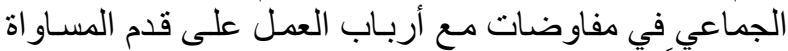

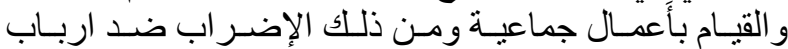

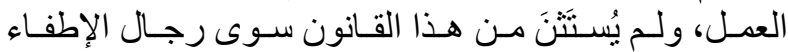

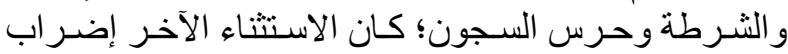

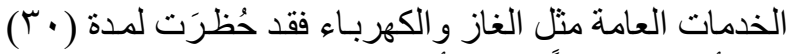

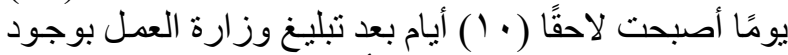

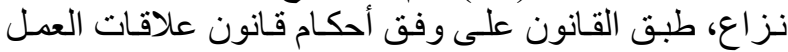

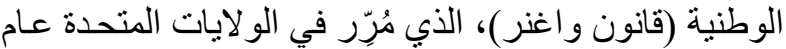

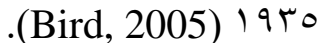

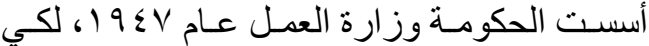

تدير وتطوّر هذا القطاع الواسع و الجديد من القانون و السياسةً

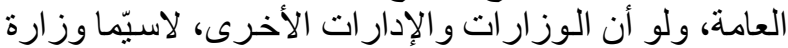

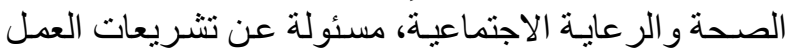

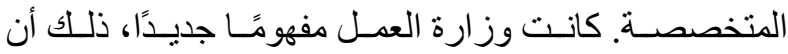

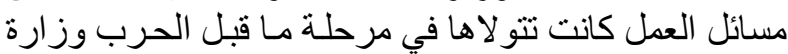
الداخلية (Levine, 1983).

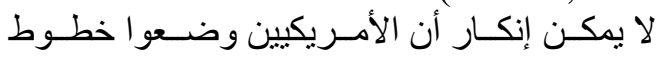

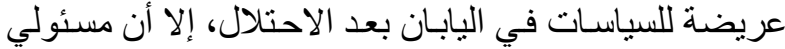

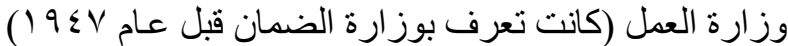

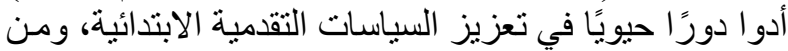

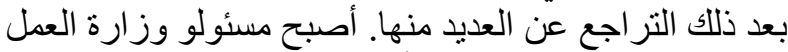

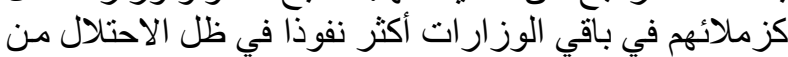

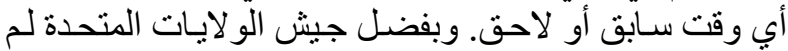

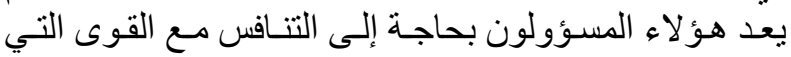

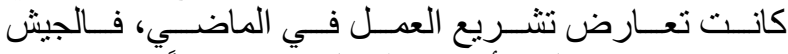

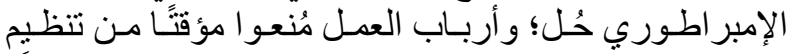

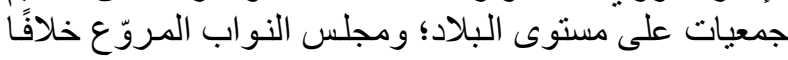

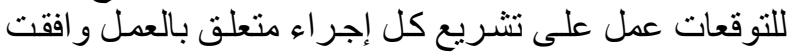

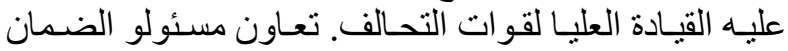
و العمل في ظل هذه الظروف بحماس مع نظر ائهم الأمريكان

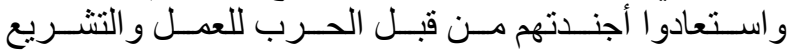

الاجتماعي (Beauchamp, 1995).

إن تجارب قبل الحرب وجهت بنحوِ مماثنل ترويج

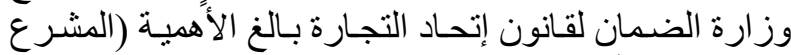

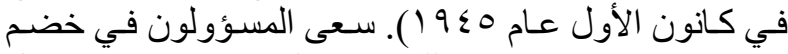

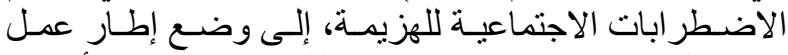

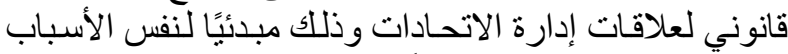

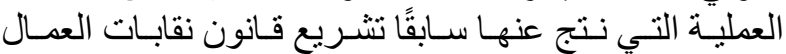

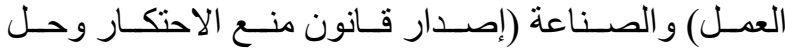

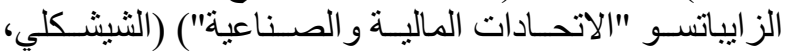

( $($ r. $)$

كانت إحدى الخطو ات الأولى للقائد الأعلى لقوات

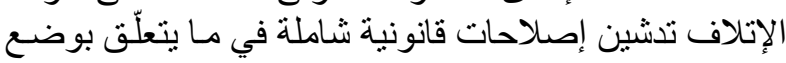

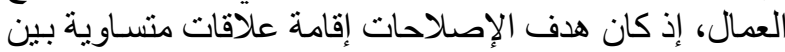

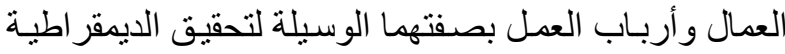

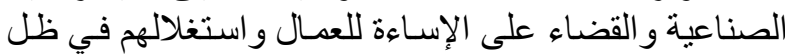

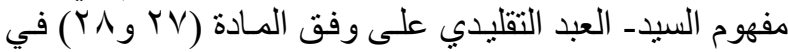
الفصل الثالث من الدستور الذي كفل حقوق الثَبع وحرياتهـ.

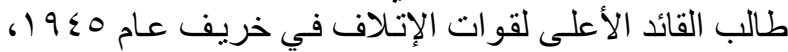
من الحكومة اليابانية بتبنّي قانون الحاد العادي العمال، وقانون العان تعديل

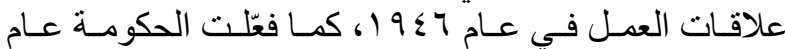

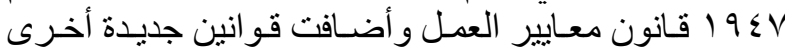

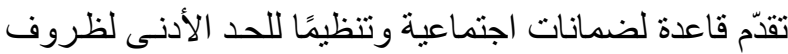

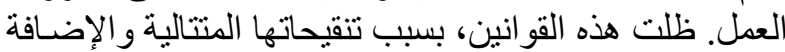

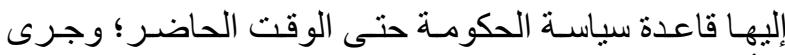

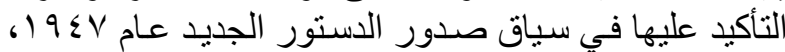
وبمقارنتها بقو انين ما قبل الحرب العالميـة الثنانيـة، فإنها تمثنّل جز

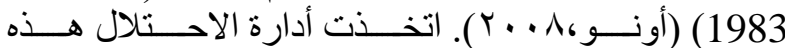

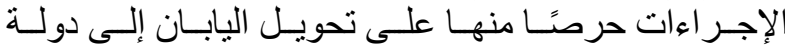

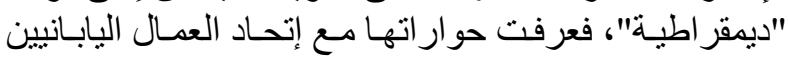

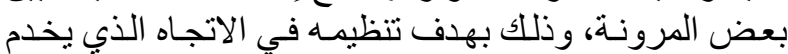

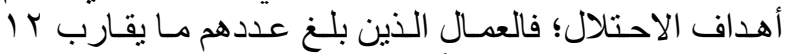

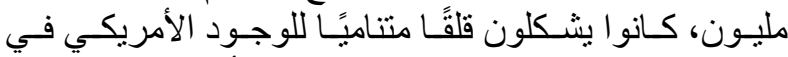

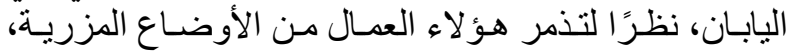

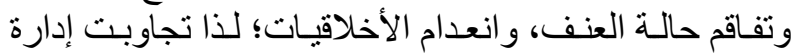

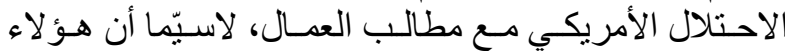

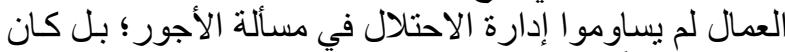

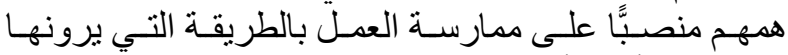

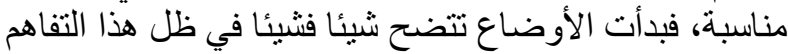

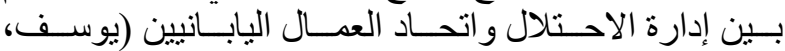

( $($. $)$.

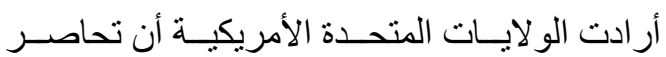

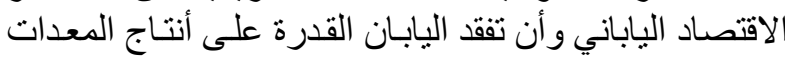

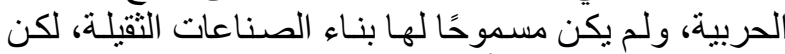

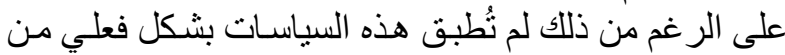

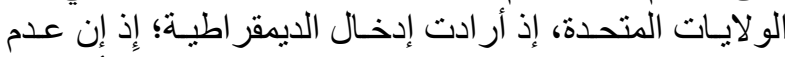

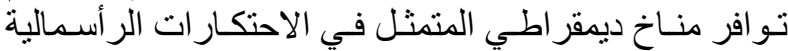

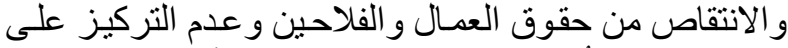

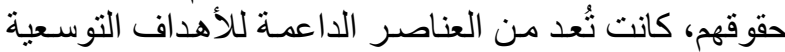

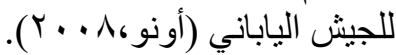

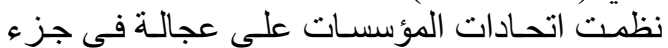

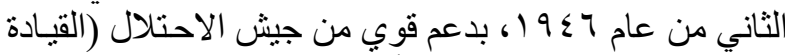

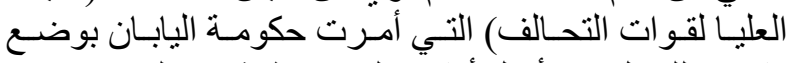

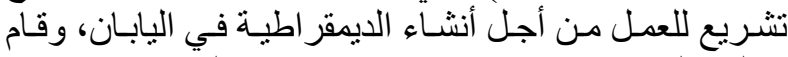

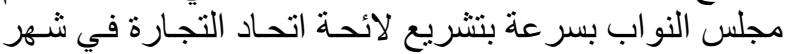

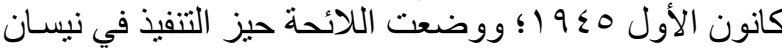




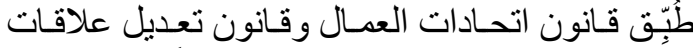

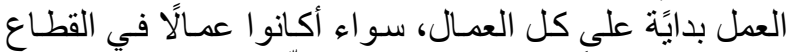

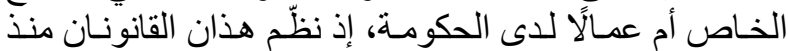

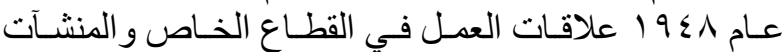

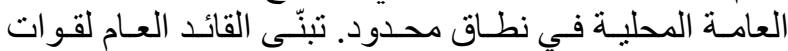

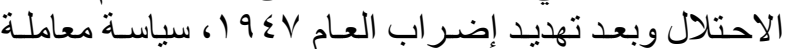

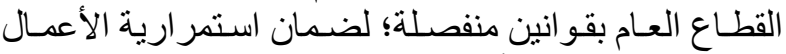

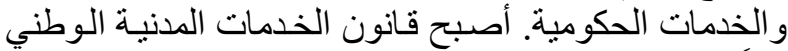

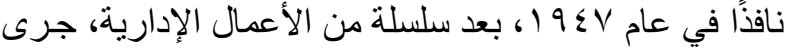

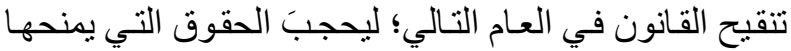

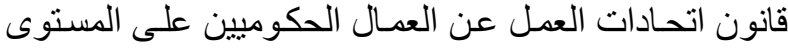

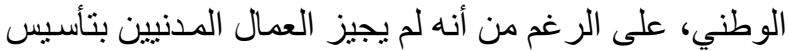

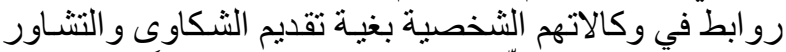

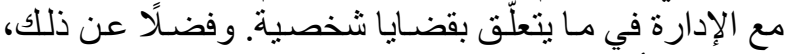

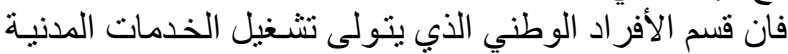

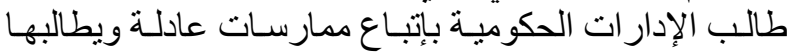

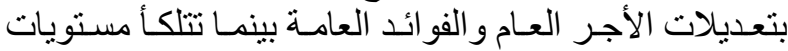

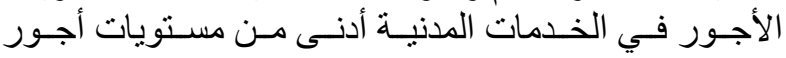

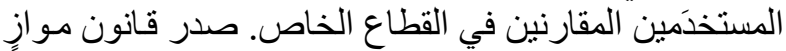

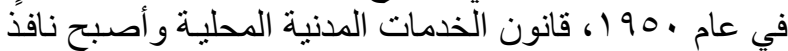

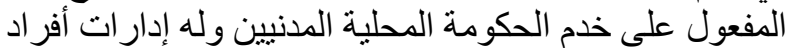

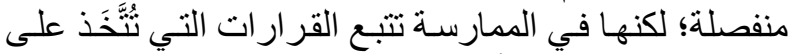

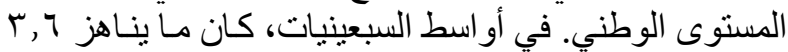

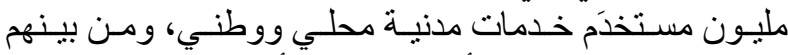

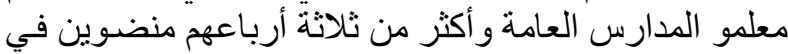

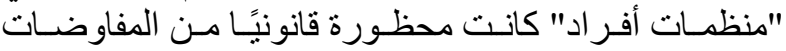

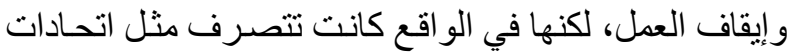

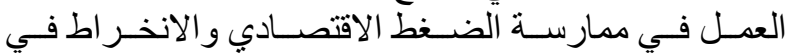
الأعمال السياسية (Levine, 1983).

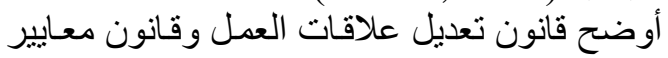

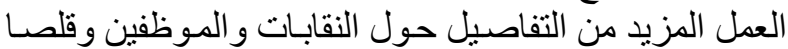

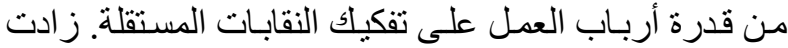

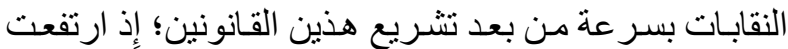

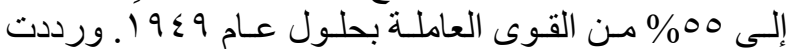

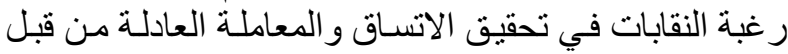

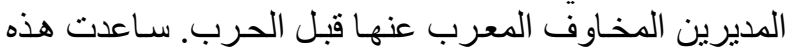

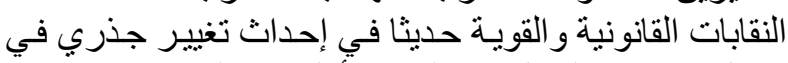

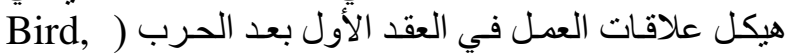
(2005

كان التغيّر الكبير الآخر قانون علاقات العمل في

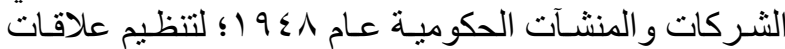

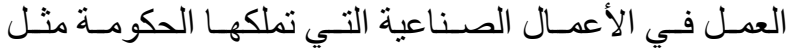

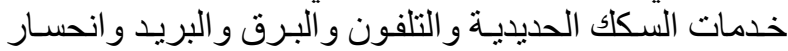
التبخ و الكحول و إدارة الغابات ومكاتب الطباعـة وسك التك النقود.

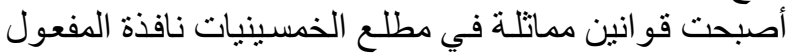

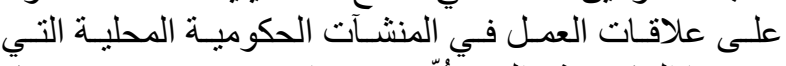

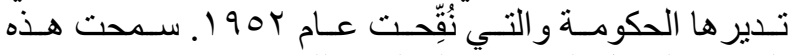

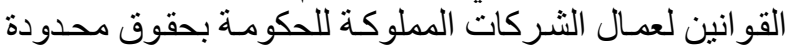

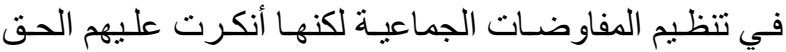

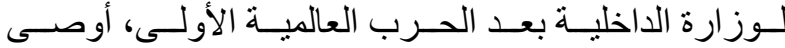

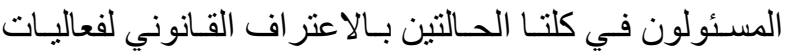

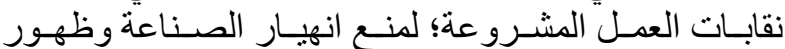
حركات عمل أكثر تشددًا (Levine, 1983).

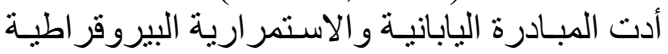

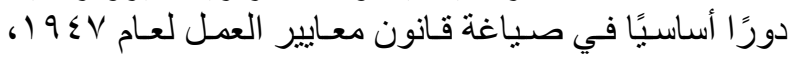

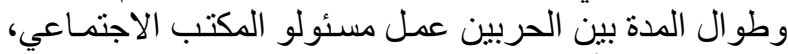

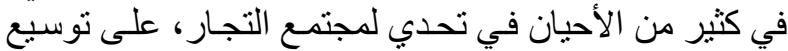

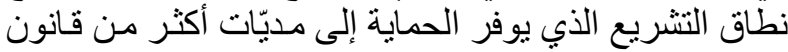

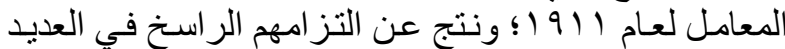

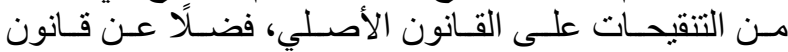

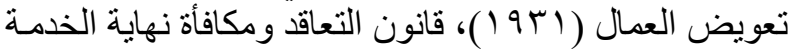

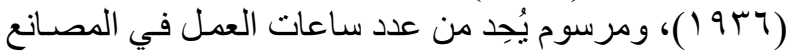

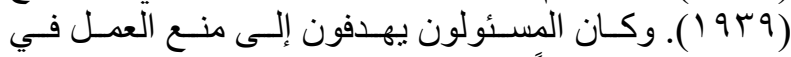

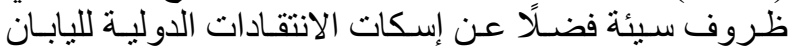

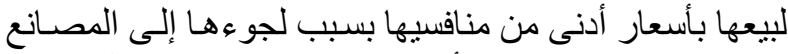

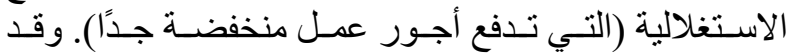
فرضت التعبئة الصناعية في وقت الحرب الترب تر اجعًا عن التنفيذ

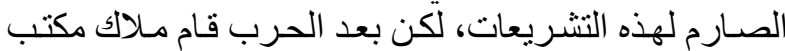

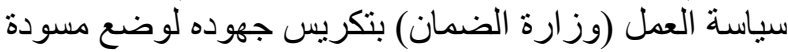

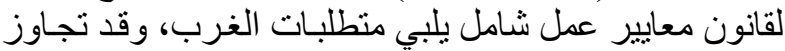

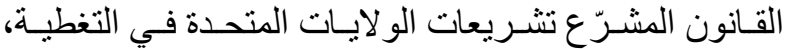

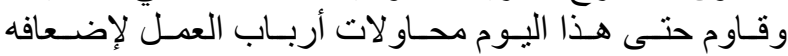

.(Beauchamp, 1995)

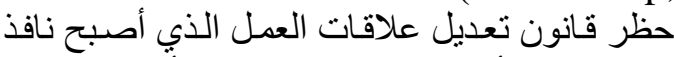

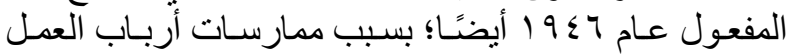

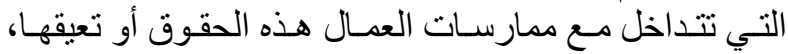

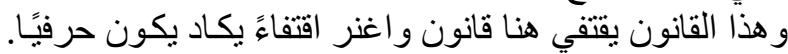

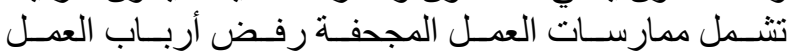

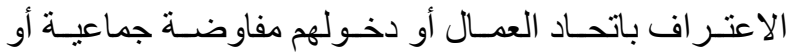

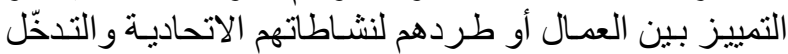

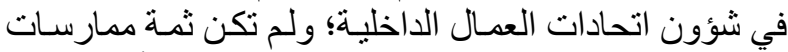

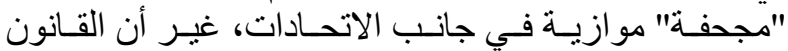

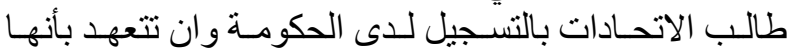

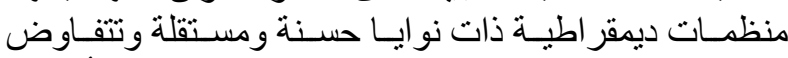

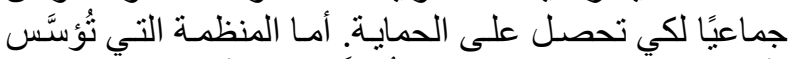

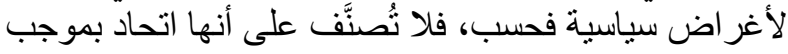

هذا القانون (Rothschild \& Natale, 1995).

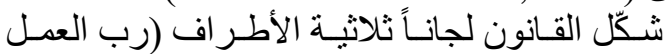

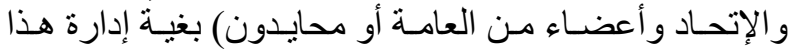

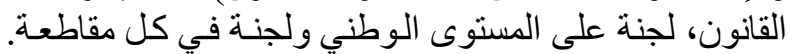
ووظائف هذه اللجان هي المساعدة في التوصل التهل إلى تسويات

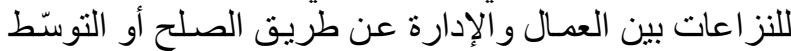

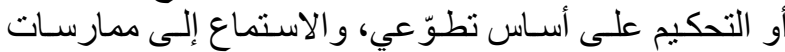

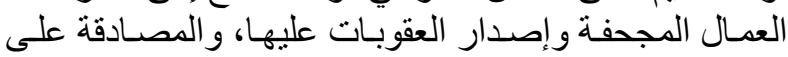

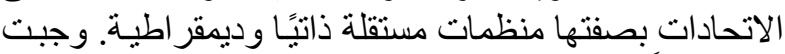

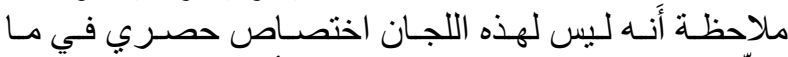

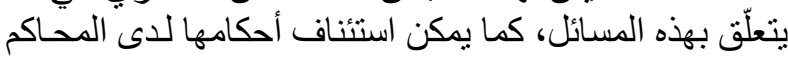
المدنية (Kazuo, Vol.4, 1983). 
لذا سعت إلى ارتقاء سلم التطور الاقتصـادي و الصناعي

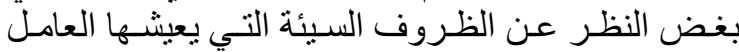

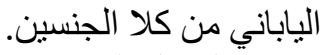

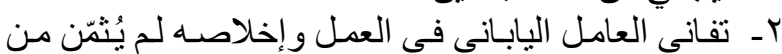

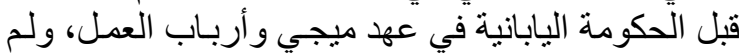

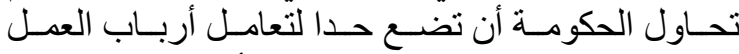
المجدف مع العمال و لاسيّما النساء و الأطفال.

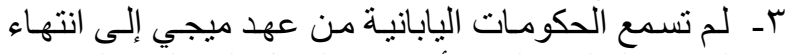

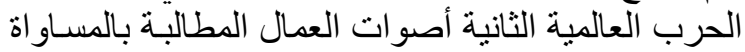

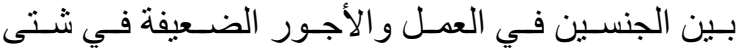
الصناعات الصنات ع - تباطؤ حكومة ميجي و الحكومـات التي تلتها حتى انتهاء

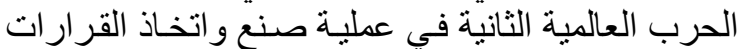

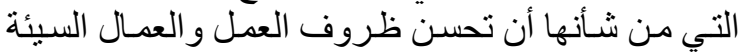

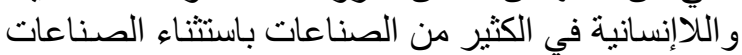

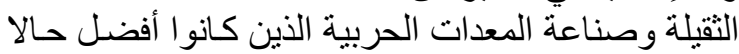
مقارنة بعمال الصناعات الأخرى.

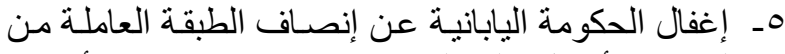

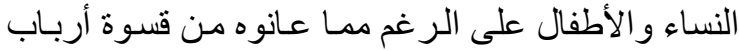

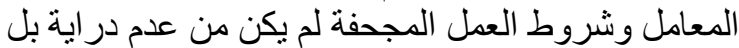
كان تقصير اكبير ا، على الرغم من الن أن النساء شكلن نسبة

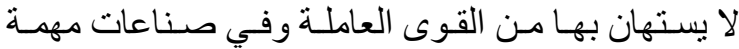

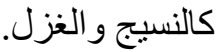

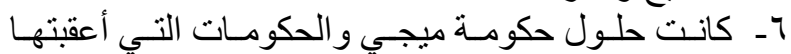

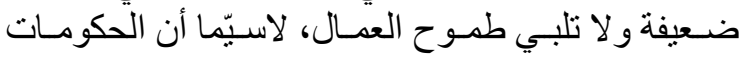

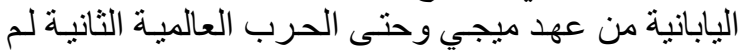

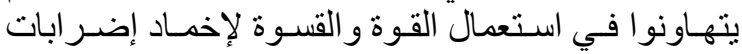

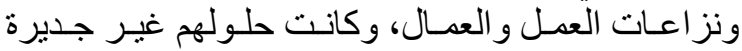
باهتمام أصحاب الحقوق من العمال.

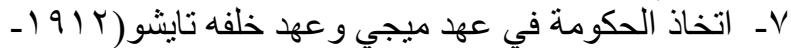

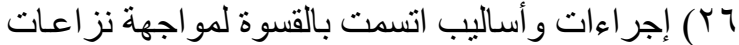

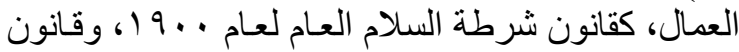

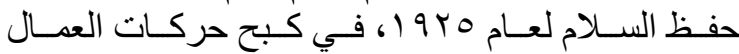

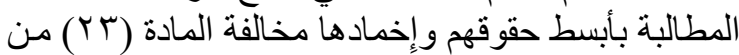

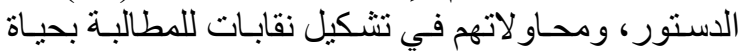

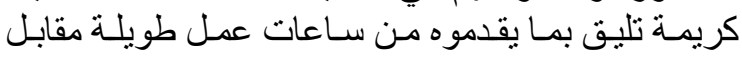

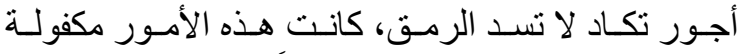

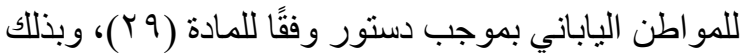

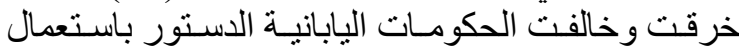

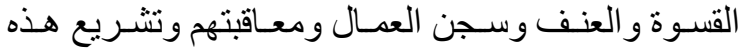

$$
\text { القو انين التي تخالف مو اد الدستور. }
$$

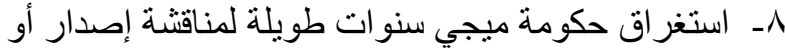

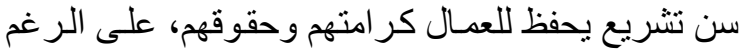

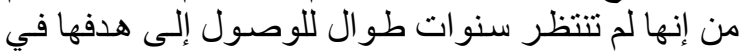

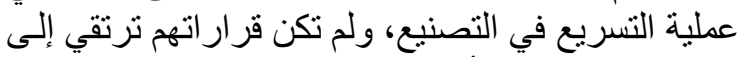

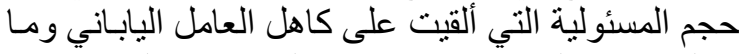

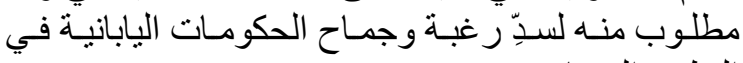
التطور الصناعي.
بالإضر اب أو القيام بإعمال نز اع مشابهة. نصّت هذه القو انين

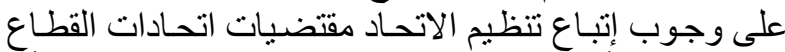

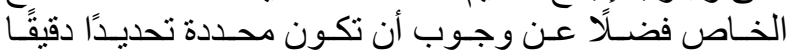

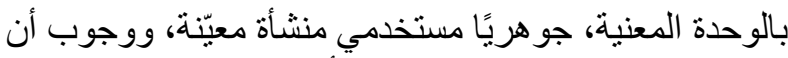

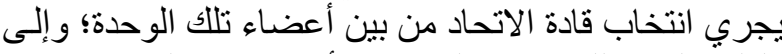

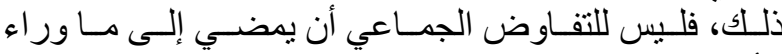

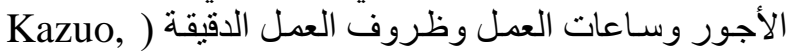

.(Vol.6, 1983

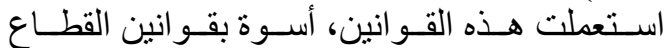

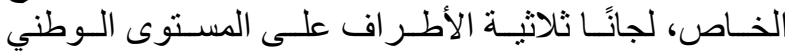

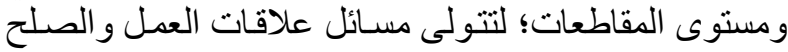

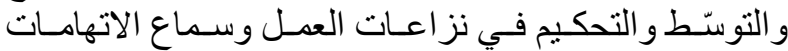

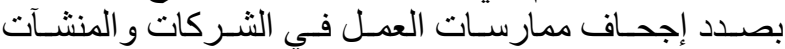

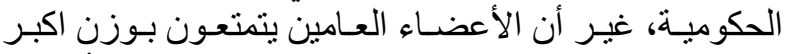

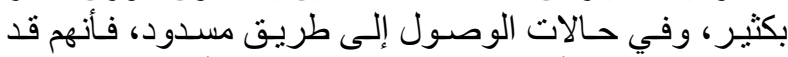

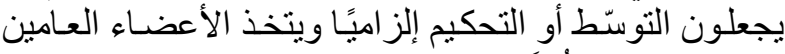

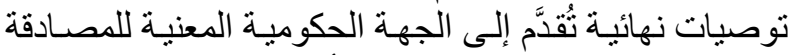

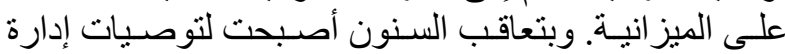

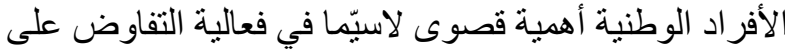

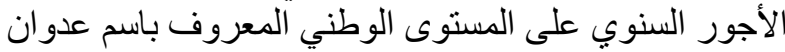

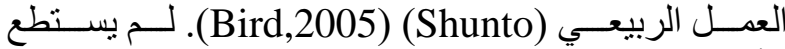

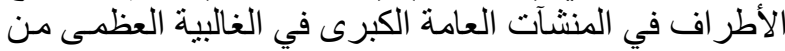

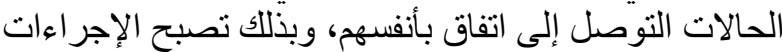

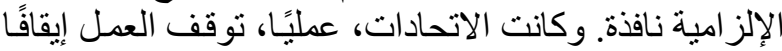

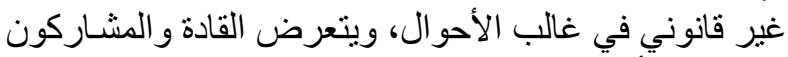

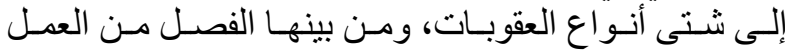

.(Haley, 1983) (Levine, 1983)

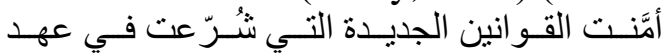

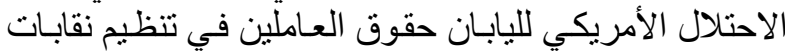

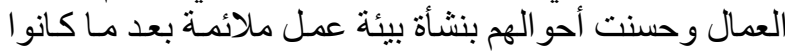

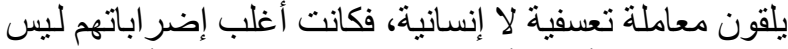

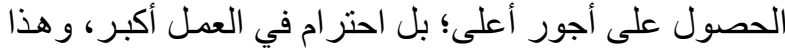

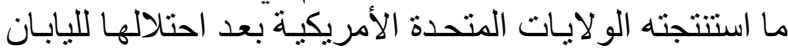

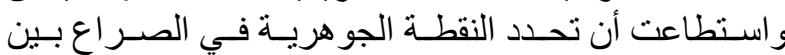

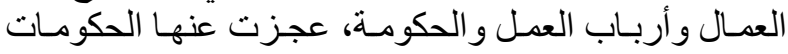

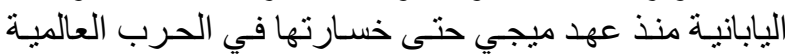

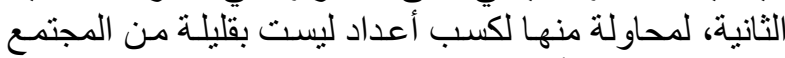

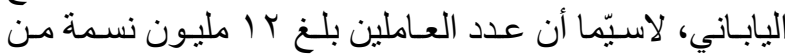

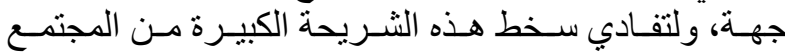

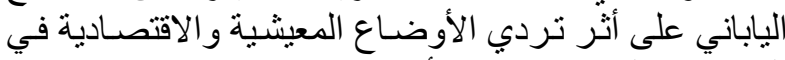
اليابان بعد الحرب من جهة أخرى الأرئ

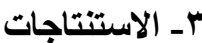

بعد در اسة واضحة لقو انين العمل في ظل دستور

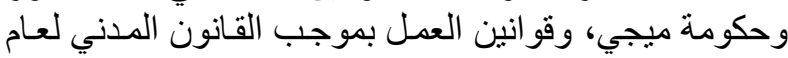

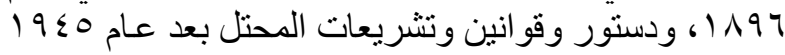

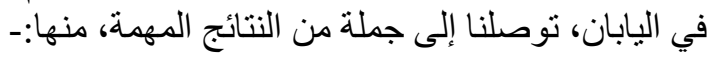

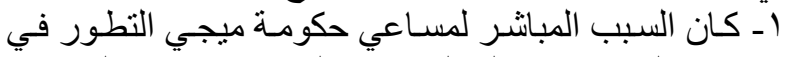

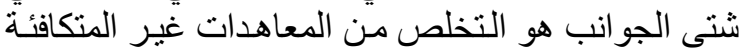
التي فرضت عليها من الولايات النتحدة و الدول الغربية. 
لعام 9 \ 9 (، بسن قو انين تحفظ للعمال حقوقهم في العمل وفي

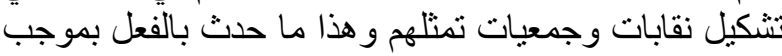

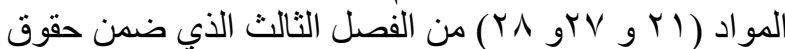

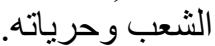

\section{المصادر العربية}

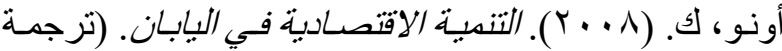

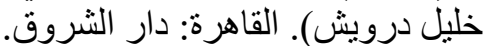

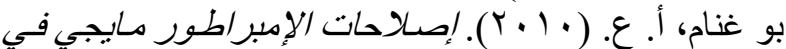

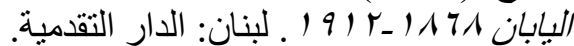

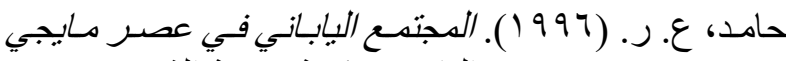

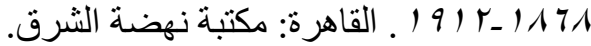

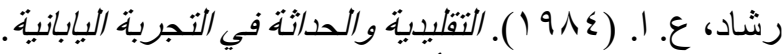
بيروت، مؤسسة الأبحاث العربية.

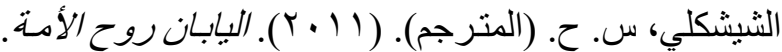

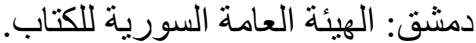

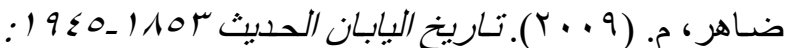

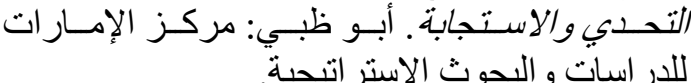

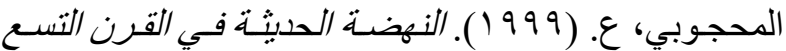
عشر: لماذا فشلت بهصر وتونس ونجدت في البابان. تونس: سر اس للنشر.

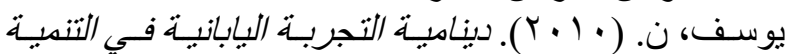

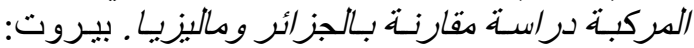
مركز در اسات الوحدة العربية.

\section{Foreign References}

Bird, A. (2005). Encyclopedia of Japanese Business And Management. New York: Routledge.

Argus, G. R. (January 14, 1911). Japan's factory law: Some needed reforms. Evening Post, LXXXI(11), Creative Commons New Zealand: NC-SA license.

Azuma, M. (1951). Labor legislation in Japan.

The Annals of the Hitotsubashi Academy, 1(2), 181-195. Tokyo, Hitotsubashi University.

Beauchamp, E. R. (ed.),( 2013). History of contemporary Japan since World War Il. New York: Routledge.

Gordon, A. (2003). A modern history of Japan from Tokugawa times to the present. New York: Oxford University Press.
9ـ شرعت الو لايات المتحدة الأمريكية وهي الدولـة المحتلـة

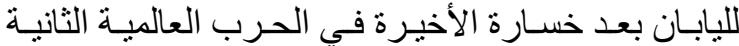

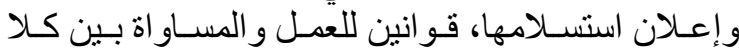

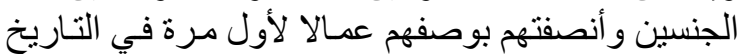

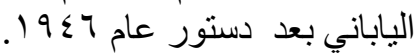

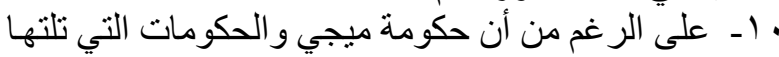

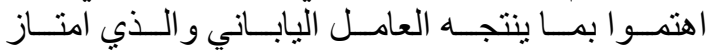

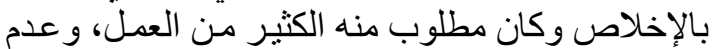

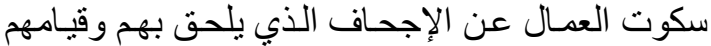

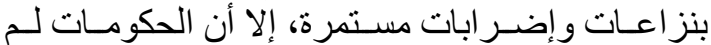

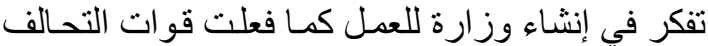

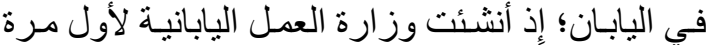
عام V 19 مان 19 11 ــ ما شر عته قوات التحالف (الو لايات المتحدة الأمريكية)

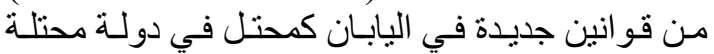

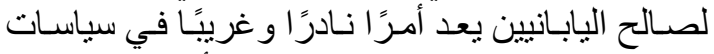

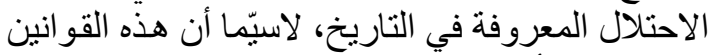

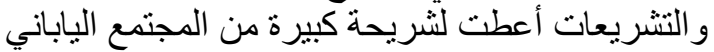
حقو قهم و هي شريحة العمال.

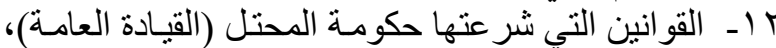

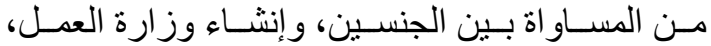

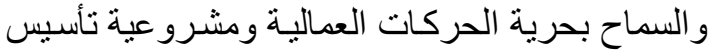

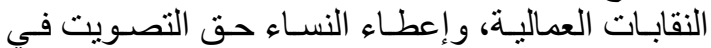

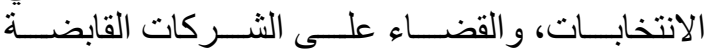

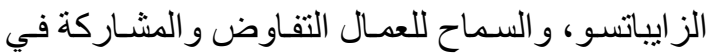

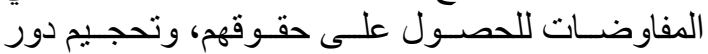

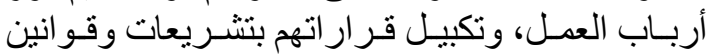

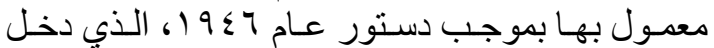

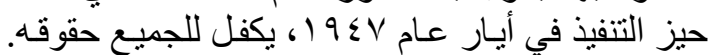

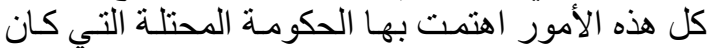

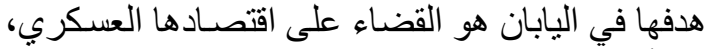

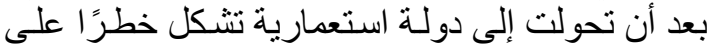

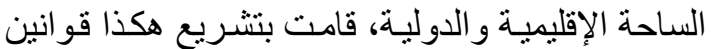

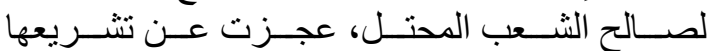

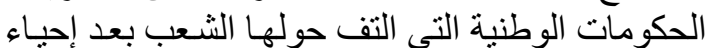

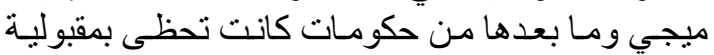

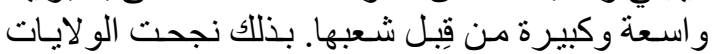

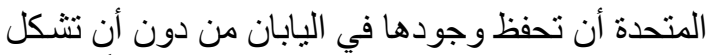

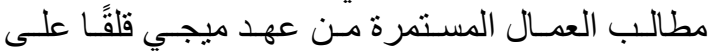
سياستها في التعامل مـع الثـعب اليابـاني بوصفه شعبا محتلا. لم تكن رغبة الولايات المتحدة في سن قوانين العمل

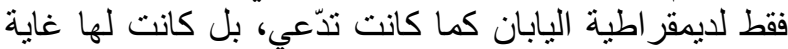

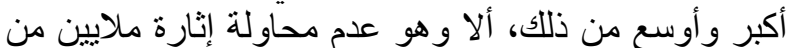

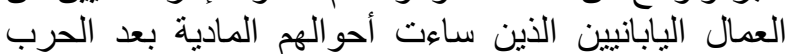

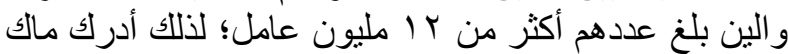

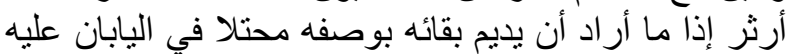

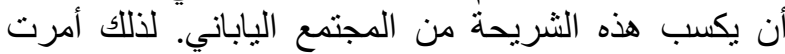

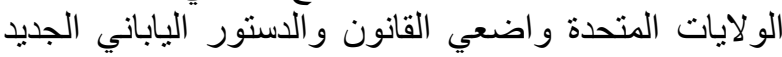


Levine, S. B. (1983). Labor laws. Kodansha, Encyclopedia of Japan. Vol.4. Tokyo: Kodansha Ltd.

Matsuoka, A. (1931). Labor conditions of women and children in Japan. Washington: United States Government Printing Office.

Maul, D. R. (2012). Human rights, development and decolonization. The International labour organization 1940-70. Geneva: Springer.

Nafzige, E.W. (2016). Learning from the Japanese: Japan's pre-war development and the Third World. New York: Routledge.

Natale, S. M., \& Rothschild, B. M.(eds.), (1995). Values, work, education: The meanings of work. Amsterdam: Rodopi.

Nimura, K. (1990). The formation of Japanese labor movement 1868-1914: An international perspective. (Translated by Boardman, T.), "Japan" in Marcel Van Der Linden \& Jürgen Rojahn(ed.). Vol. II. Retrieved from http://nimuralaborhistory.jp/English/enformation.html

Ono, S. (1996). Comparative law and the civil code of Japan (1). Hitotsubashi Journal of Law and Politics, The Hitotsubashi Academy, (24), 27-45.

Tiedemann, A.A.(1974). An introduction to Japanese civilization. New York: Columbia University Press.

Van Den Berg, P. (Feb., 2018). Politics of codification in Meiji Japan (1868-1912): Comparative perspective of the position of customary law in Japanese civil code. Osaka University Law Review, (65), 6988.

Wein, M. (1989). The origins of the Korean community in Japan, 1910-1923. Manchester, Manchester University Press.
Gordon, A. (1997). Workers movements in late Meiji Tokyo. Bulletin de l'Ecole Française D'extrême-Orient, 84, 285-308.

Gordon, A.(2018). Social conflict and control, protest and repression (Japan). International Encyclopedia of the First World War in: 1914-1918online.

DOI:

10.15463/ie1418.11253.https://encyc lopedia.1914-1918-

online.net/article/social_conflict_and _control_protest_and_repression_jap an

Haley, J. O. (1983). Public employees. Kodansha, Encyclopedia of Japan,6, 264-265.

Harari, E. (1973). The politics of labor legislation in Japan. Los Angeles: University of California Press.

Hiroshi, E., (1983). Civil code. Kodansha. Encyclopedia of Japan. Vol. 1.Tokyo: Kodansha Ltd.

Hoffmann, F. (2011). Legal authenticity, cultural insulation and undemocratic rule: 'Abd-alRazzaq Ahmed al-Sanhuri's (1895-1971) sharia project and its misrepresentation in Egypt. In cultural transfers in dispute: Representations in Asia, Europe and the Arab World since the Middle Ages. Frankfurt: Campus Verlag.

Hotani, R. \& Hayashi, T. (Oct., 1961). The evolution of wage structure in Japan. Sage Publications, Inc. Labor Relations Review, 15(1), 52-66.

Kazuo, S. (1983). Labor dispute resolution procedures. Kodansha, Encyclopedia of Japan. Vol.4. Tokyo: Kodansha Ltd.

Kazuo, S. (1983). Public corporations and government enterprises labor relations law. Kodansha, Encyclopedia of Japan, Vols.Vol.6. Tokyo: Kodansha Ltd.

Kodansha. (1983). Encyclopedia of Japan.Vol.1, Tokyo: Kodansha Ltd. 